Bull. Fac .Agric., Cairo Univ., 68:223-236 (2017).

\title{
DIAGNOSING ORGANIZATIONAL CULTURE OF AGRICULTURAL EXTENSION CENTERS IN ASSIUT GOVERNORATE
}

(Received: 8.7.2017)

\author{
By \\ M. M. M. Abdel-Ghany \\ Department of Rural Sociology \& Agricultural Extension, Faculty of Agriculture, \\ Assiut University, Assiut, Egypt
}

\begin{abstract}
This study aimed at diagnosing organizational culture of agricultural extension centers in Assiut Governorate by identifying the current and preferred organizational culture types, and the gap between them from the viewpoint of extension centers' employees in Assiut Governorate. The study used the instrument developed by Cameron and Quinn (2006) to diagnose the organizational culture according to the competing values framework. Data were collected from all the agricultural extension centers' personnel in Assiut Governorate (58 personnel) by a questionnaire during the period from March to April 2017. Frequencies, percentages and mean scores were used for data presentation. The results showed that the hierarchy culture is the dominant culture of the agricultural extension centers in Assiut Governorate, and the clan culture is the preferred organizational culture. The gap between the current and the preferred organizational culture can be summarized in the desire of the respondents to increase the characteristics of both clan and adhocracy cultures, as opposed to their interest in reducing the characteristics of both hierarchy and market cultures. The study recommended that the agricultural extension centers in Assiut Governorate should move from the current hierarchy culture to the desired clan culture, taking into account the considerations that should be complied when changing the organizational culture of agricultural extension centers in Assiut Governorate.
\end{abstract}

Key words: Diagnosing Organizational Culture, Competing Values Framework, Agricultural Extension Centers, Assiut Gov., Egypt.

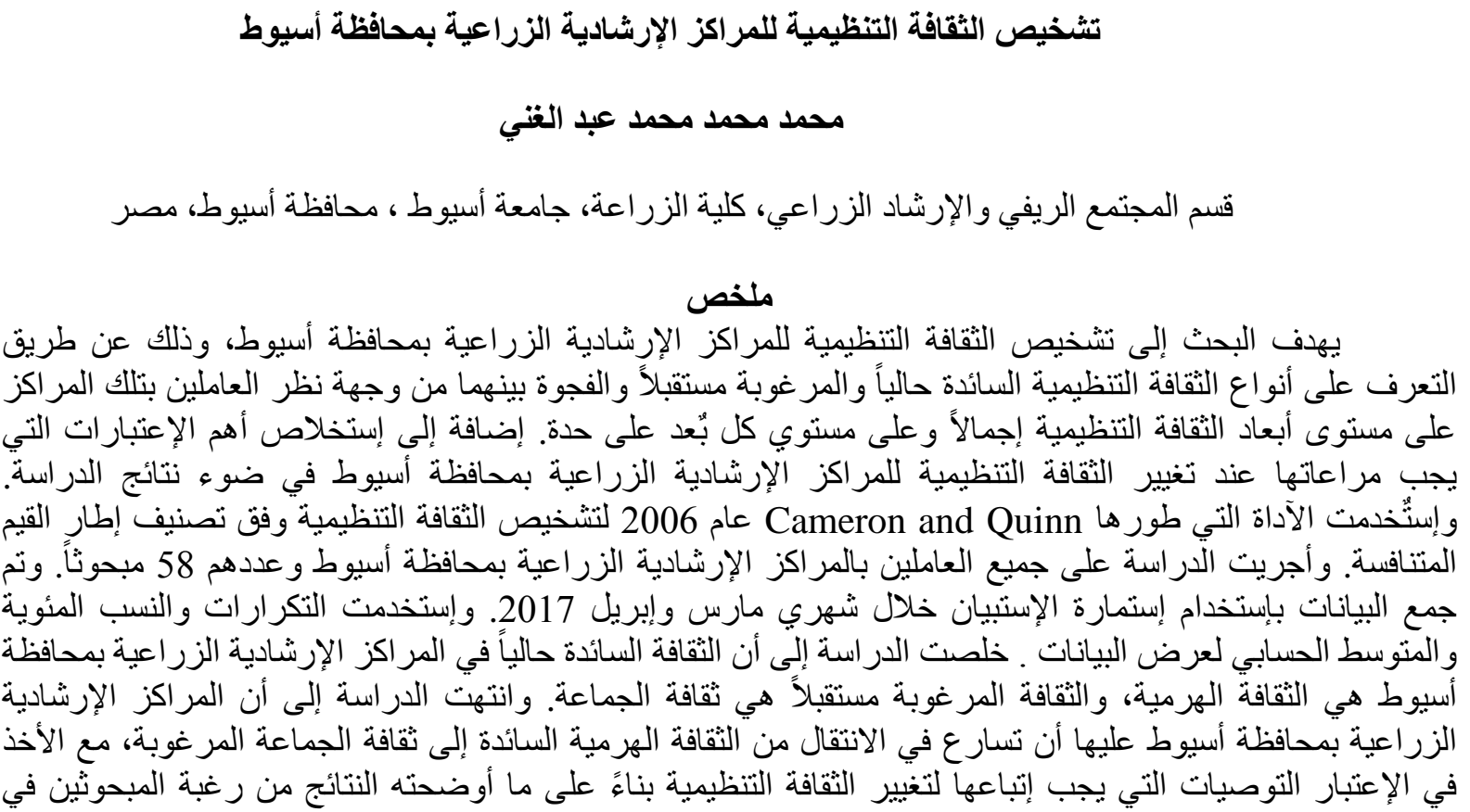


زيادة خصائص كلاً من ثقافة الجماعة و الثقافة الإبداعية، في مقابل تقليص خصائص كلاً من ثقافة السوق و الثقافة الهرمية على مستوى جميع أبعاد الثقافة التنظيمية.

يتطلب الإلمام بكيفية إدر اك العاملين بالمنظمة لتلك الثقافة،

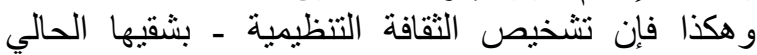

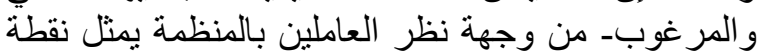

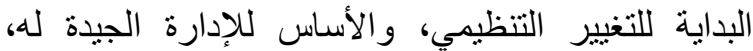

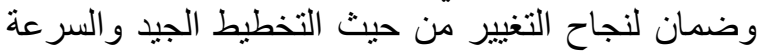
المناسبة وتمشيه مع ظروف لنير المنظمة وتجنب مقاومة

(Cameron and Quinn, 2006; التغيناسير .Tharp, 2009; Hämmal and Vadi, 2010) وفيما يتعلق بالعمل الإرشادي، تحتاج المنظمات العاملة

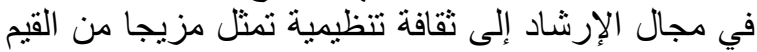

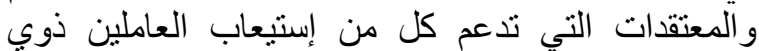
الخلفيات والقدرات المختلفة، وتقديم الخدمات الإرشادية الخدادية للمستهدفين لتحقيق الفعالية التنظيمية للمنظمة الإرشادية.

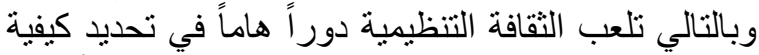
قيام العاملين بالإرشاد بتخطيط وتنفيذ وتقييم الأنشطة Schauber, 2001)

و البرامج الإرشادية ,Berrio,2003 )

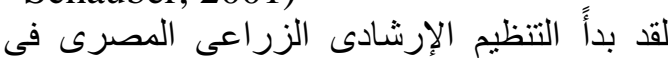

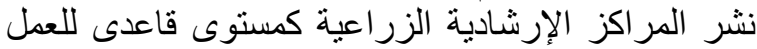

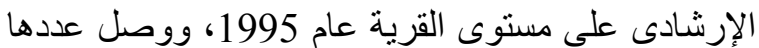

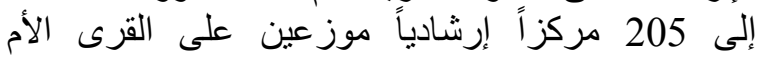

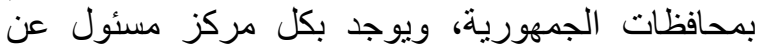
المركز ومعله مجموعة من الأخصائية وبين الإرشاديين

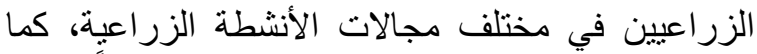
يوجد بالمركز قاعة تدريب تسع لعدد 60 فرداً مؤثثنه ومجهزة بالأجززة السمعية والبصرية لتعقد الإجتماعات

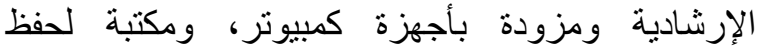

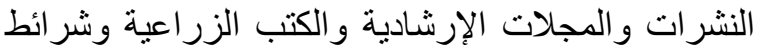

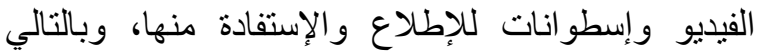

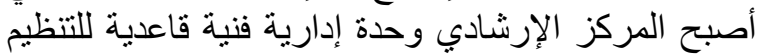

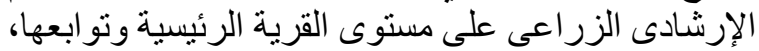

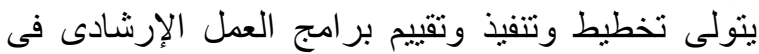

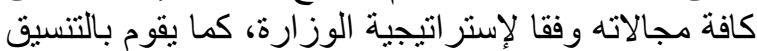

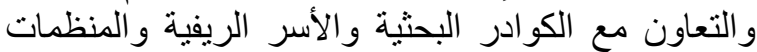

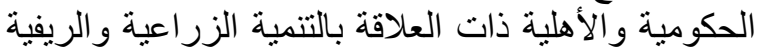

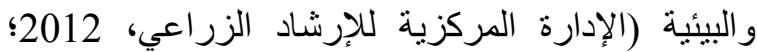

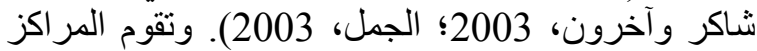

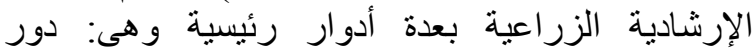

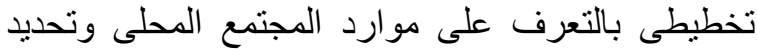

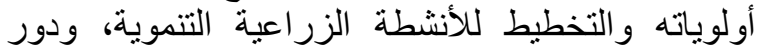
تدعيمى للإسهام فى حلى لل المشكلات الريطية الرية الزية الزراعية

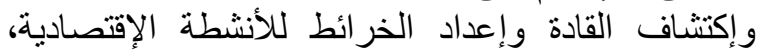

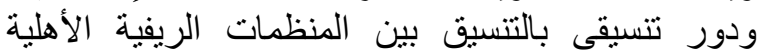

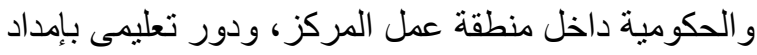

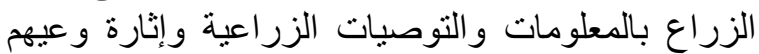

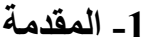

تعتبر الثقافة التنظيمية خاصية فريدة تميز كل منظمة على حده وتترسخ في سلوك أفر ادها، وينم إدارنها تُبنا

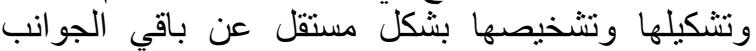

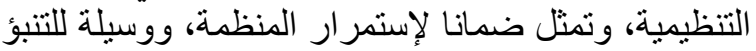

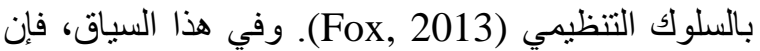

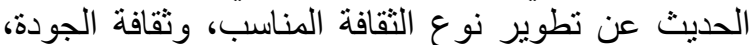

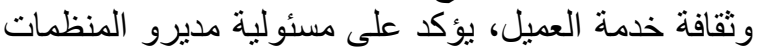
عن تشكيل الثقافة التنظيمية عن طريق القيم التئ التي يحاولون التئن

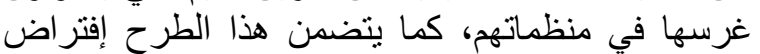
وجود ثقافة جيدة وأخرى سيئة، وثثافة قوية والخية وأخرى

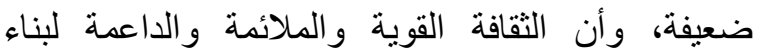

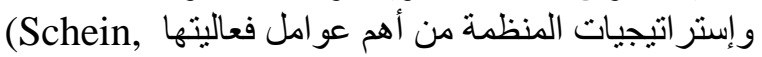
.2004)

وتمثل الثقافة التنظيمية أحد أهم العو امل المسئولة

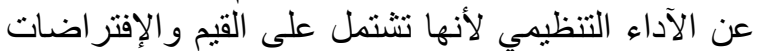

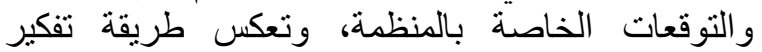
أعضاء المنظمة، وتنقل إليهم الإحساس بالهات بلهوية التنظيمية. كما تمدهم بالإرشادات و التوجهات التهاصة الإحة بكيفية التعامل وسير العمل داخل المنظمة. وكلما إثتندت المنادية المنافسة والضغوط والتغيرات التي نتعرض لهات لها المنظمة، كلما

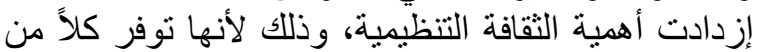

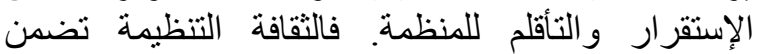

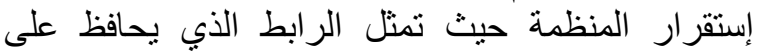
إستمرار و إستقرار المنظمة عن طريق الإلتزام بالقيم

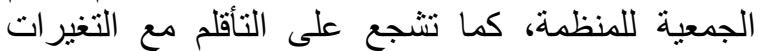
الحادثة كونها تمثل المرجع الذي تستمد مناعه المبادئ التي التي التئي

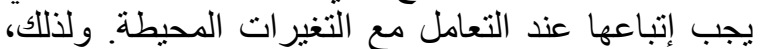

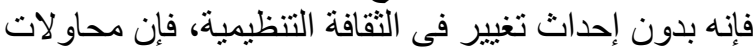
تغيير الجوانب التنظيمية الأخرى لن تصل لإن للنتائج المطلوبة فيما يتعلق بالتحسين الدائم للآداء التنظيمي، وينز ايد هذا لإنيا

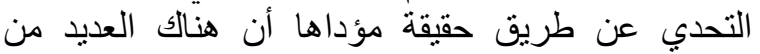

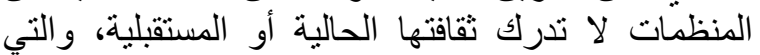

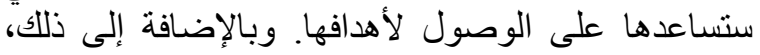

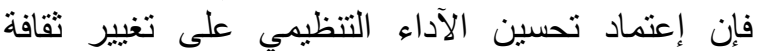

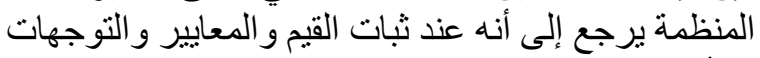

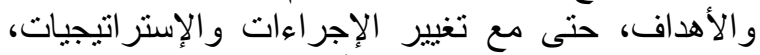

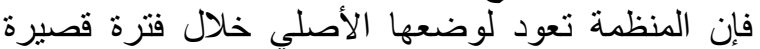

.(Cameron and Quinn, 2006) وقد ذكر García et al. (2012) أن الثقافة

التنظيمية مصطلح يصف كيفية إدراك العاملين بالمنظمة أنسافة

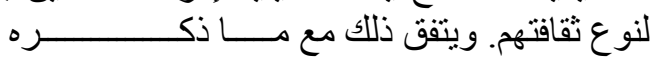
Karthikeyan et al. (2008) تعبر عن الإدراكات المشتركة للعاملين بالمنظمة والتي التياني

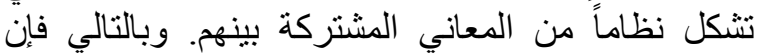
معرفة المزيد حول الثقافة التنظيمية والإدارة الجيدة لها لهان 
المناخ التنظيمي (طريقة تفاعل أعضاء المنظمة مع العمارئ

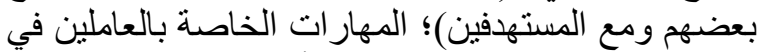
تنفيذ مهام العمل؛ طرق التفكير (الأطر المعرفية المشتركة

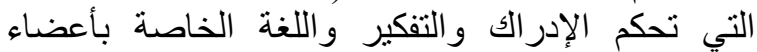

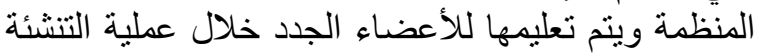

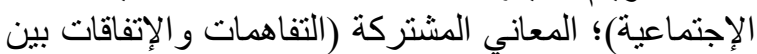

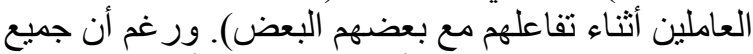

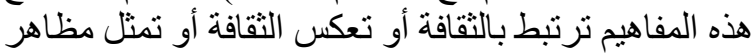

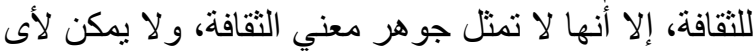

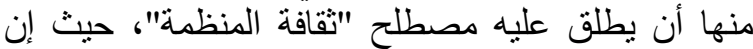
كلمة الثقافة تضيف عدة أبعاد هامة للمفاهيم السابقة مثل: الثبات البنائي Structural Stability (فالثقافة تمثل قوة النقائة

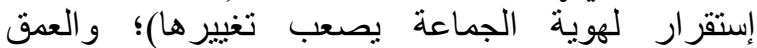

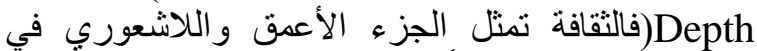
الجماعة، و الأقل ظهور اً وملموسية من الجو الب الب الأخرى)؛

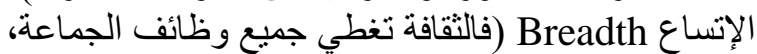
وتؤثر في كافة الأبعاد المتعلقة بكيفية تعامل المنظمة مع الفي

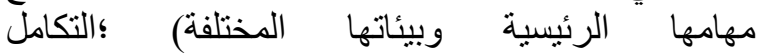
Intergration

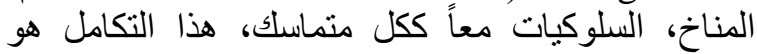
جو هر ما تعنية كلمة "الثقافة" (Schein, 2004). ويُنظر للثقافة التنظيمية على أنها تلفية تمثل البصمة

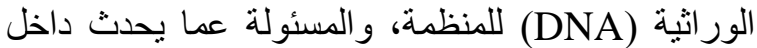

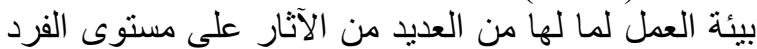

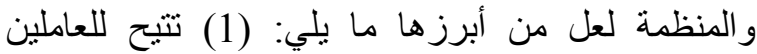
بالمنظمة فهم تاريخها وكيفية سير العمل بلمان بها، بما يمثل

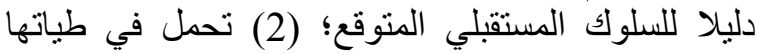

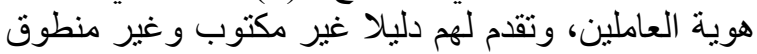

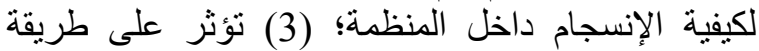

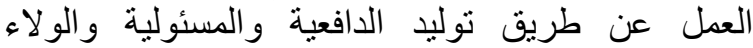
للعاملين بالمنظمة؛ (4) تتوقف مهارة القادة داخل المنظمة

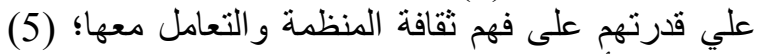
تؤثر على أخلاقيات و إلتز ام و إنتاجية العاملين؛ (6) تؤثر

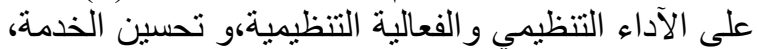
ومستويات التقييم، وتسهيل حدوث التئيل التغيير أو منعه بناءًا

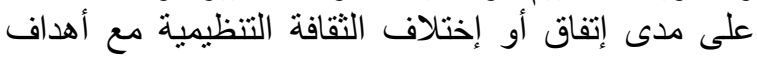

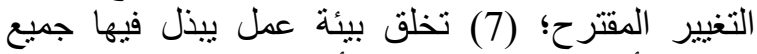

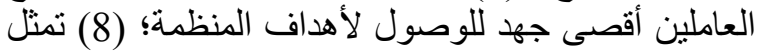

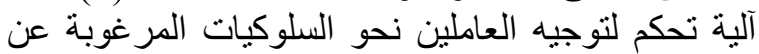

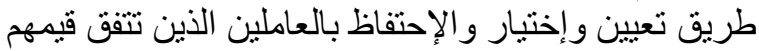

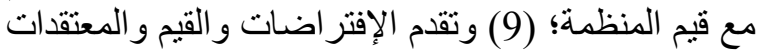

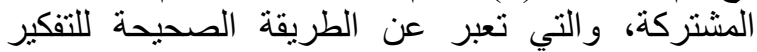

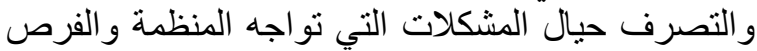
المتاحة أمامها Lunenburg, 2011; García et al., 2012; Adewale and Anthonia, 2013; Tănase, 2015) و هناك عدة مستويات للتقافة التنظيمية (يشير

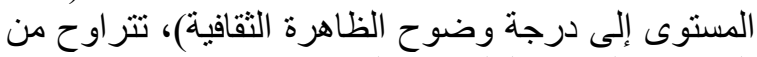
المظاهر المادية الملموسة التي يمكن رؤيتها (وتتضدن ترن
بالمستجدات و إنشراكهم فى البرامج الإرشادية الريفية

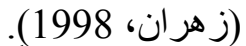

وإستناداً للعجالة السابقة، يتضح جلياً أهمية تشخيص الثقافة التنظيمية للمراكز الإرشادية الزراعية،

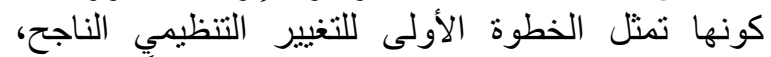

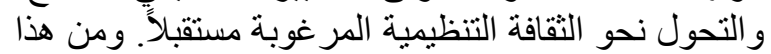
المنطلق، يهدف البحث الحالي إلى تثخيص التربة الثقافة

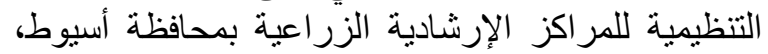
وذلك عن طريق التعرف على الأنواعة النياع الثقافة التنظيمية

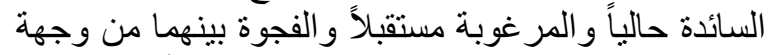
نظر العاملين بتلالك المراكز على على مستوى أبعاد الثقافة

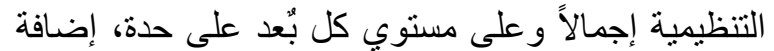

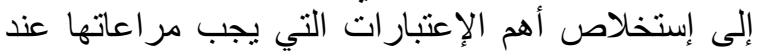

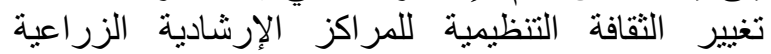
بمحافظة أسيوط في ضوافو الإطة نتائج الدر اسة. 2- 2- الإطار النظري 1-2 الإطقافة التنظيمية

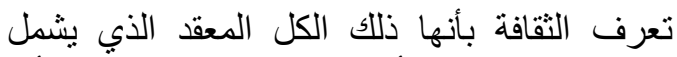

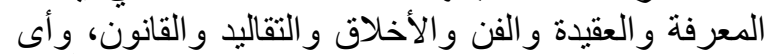

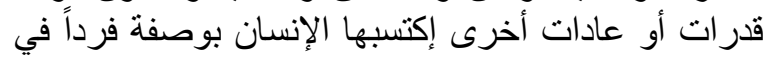

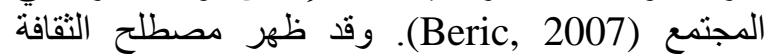

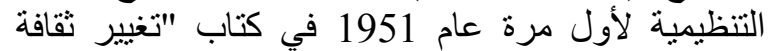
المصنع"، ونم التعبير من خلاله عن الأبنية الإجتماعية

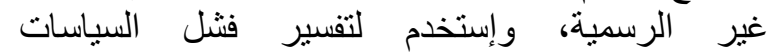
و الإجراءات الرسمية في تحسين العلاقات بين الرين الرؤساء و المرؤسين (Denison et al., 2014). ويتفق العديد من الباحثين على أن الثقافة التنظيمية

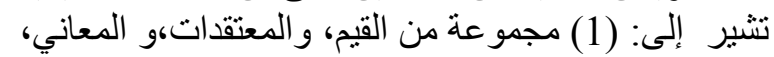

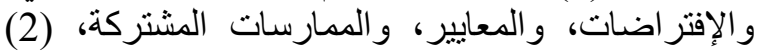

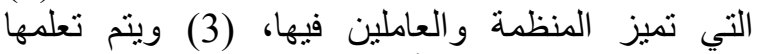

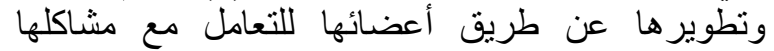
المتعلقة بالتأقلم مع البيئة الخارجية، و والتفاعل الداخلي بين

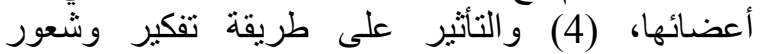
وتصرف العاملين في بيئة العمل، (5) كما أنها لا تلاحظ فئس

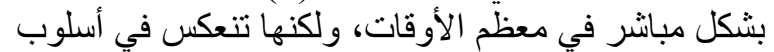

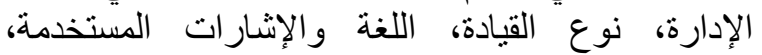

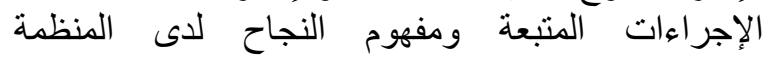
(Schein, 1990; Cameron and Quinn, 1999; Schein, 2004; Igo and Skitmore, 2006; Suderman, 2012; Adewale and Anthonia, 2013; Woszczyna, 2014).

و هناك عدداً من المفاهيم التي تعكس الثقافة

ويتشاركها العاملون بالمنظمة مثل: السلّوكيات الإعتبادية

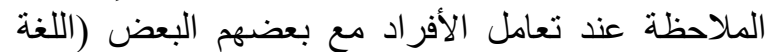

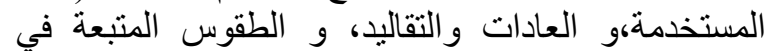
المو اقف المختلفة)؛ القيم و المعايير(الأسس التئ التئي يتفق عليها

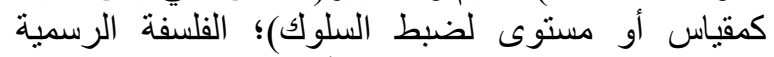

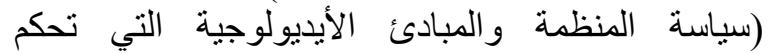
سلوكيات المنظمة تجاه العاملين و المستهدفين والثركاء)؛ 
و الوضع الذي تريد ،أو يجب ، أن تصل إلبه)، كما أن الن إنة

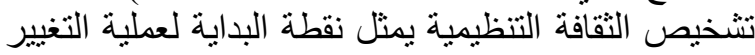

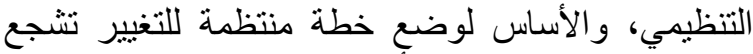
العاملين وتستغل طاقاتهم و أفكار هم بما يدعم التغيير ، وذلتك

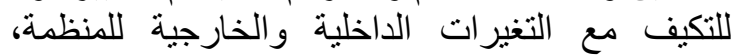

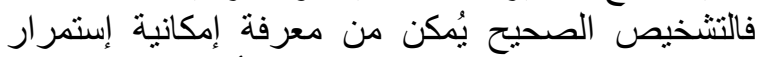

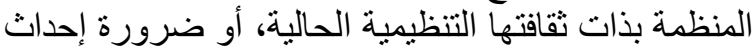

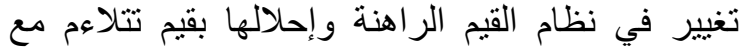

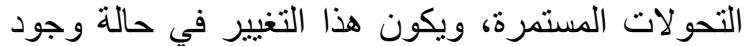
فجوة بين الثقافة الحالية و الثقافة المرغوبة (بركة، 2012 2016،

سالم، 2006؛ (OCAI online, سون 2012. 206 (2) وقد طور(2006) آداة

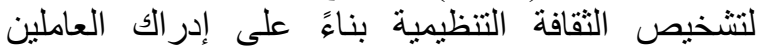
بالمنظمة لأبعاد أو جو انب الثقافة التنظيمية، وذللك لتقديم

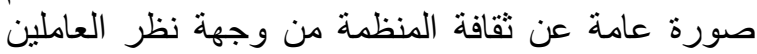
بها، وقد تم إستخدام هذه الآداة في اكثر من ون 1000 منظمة الفي

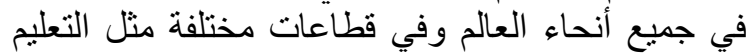
و الآصحة ومنظمات التهاء التكنولوجيا ومنظمات ونات المجتمع المدني

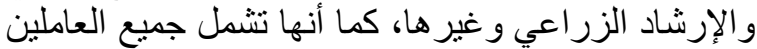

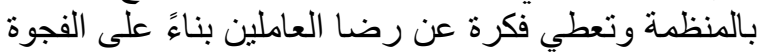

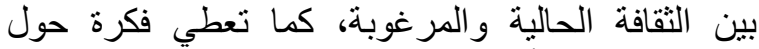
طبيعة التغيير الأمثل في ظل الثنة الثقافة التنظيمية المرغوبة

.(Cameron and Quinn, 2006; Berrio, 2003) وتننى آداة تشخيص الثقافة التنظيمية على نموذج

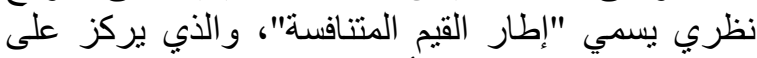

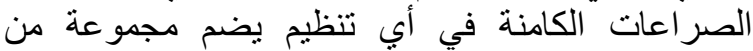
الأفر اد، وبشكل خاص الصراع الصاع مابين الإستقرار و التغيير

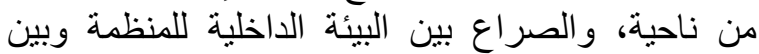

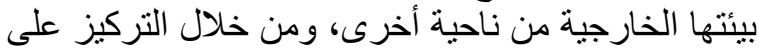
هذه الصر اعات الكامنة في الحياة التنظيمية يمكن معرفة التئة التناقضات والظواهر المثبطة لتحقيق الفعالية التنظيمية

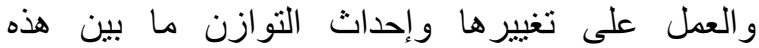

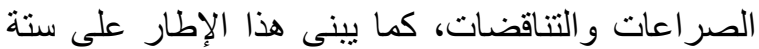
أبعاد للنقافة التنظيمية وأربعة أنواع رئيسية لتلإلك الثقافة.

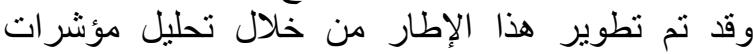

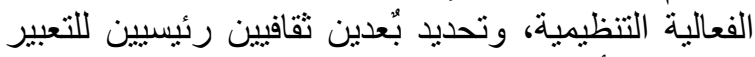

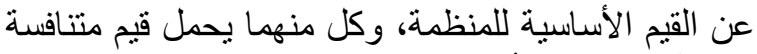

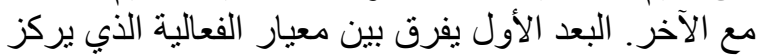

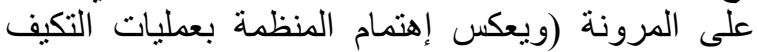

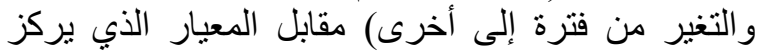

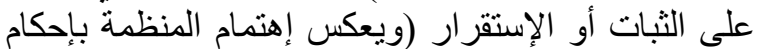

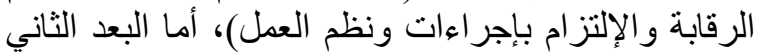

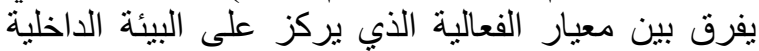

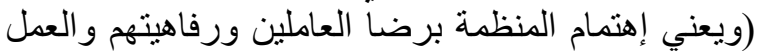
على زيادة كفاءتهم ومهار اتهم في العمل) مقابل العابل المعيار

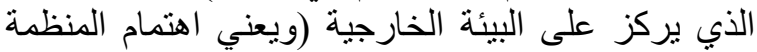

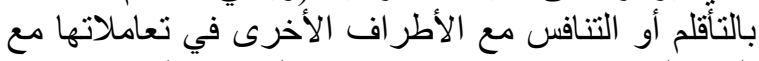

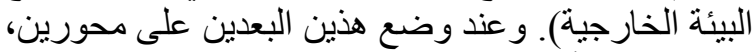
فإنهما يشكلا أربعة خلايا تعبر كل منها عن مجموعة من لئن

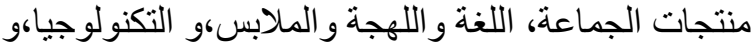

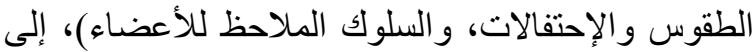

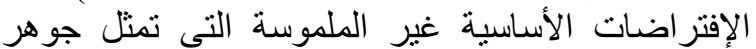
الثقافة (الإجماع والإتفاق في الآراء بين أعضاء الأتئ الجماعة

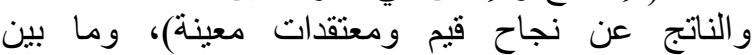

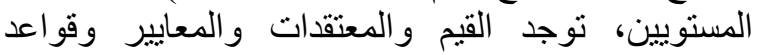
السلوك (Schein, 2004). وقد تم التعبير عن الثقافة

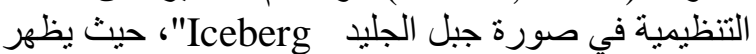
الجزء الأصغر فقط الذي يمثل الأبعاد الرسمية للتقافة

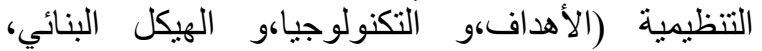

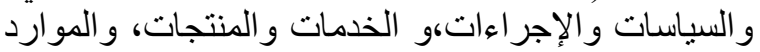

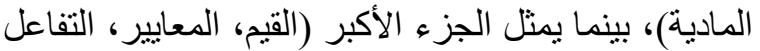

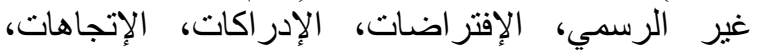

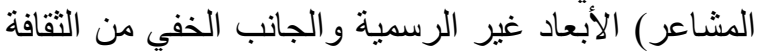

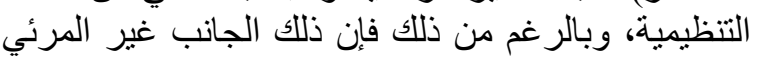

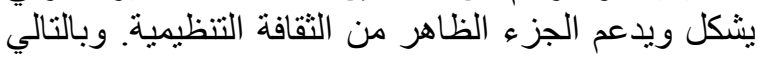

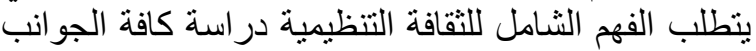
المرئية وغير المرئية لها (Fox, 2013). 2-2 تثخيص الثقافة التظيمية

يعبر التشخيص عن تحديد طبيعة أو سبب الثئه الثئه

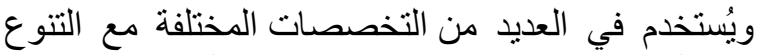
في الهدف من الإستخدام، ومن هذه المجالات تطوير

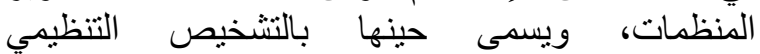

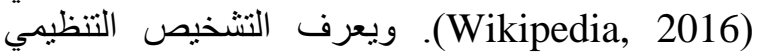
بالعملية التي تعتمد على جمع وتحليل البيانات التنظيمية

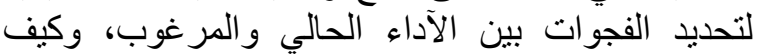
يمكن تحقيق المنظمة لأهدافها وطبيعة التغيير التئي التظيمي المناسب (Rapidbi, 2007). ويعتبر التشخيص الثقافي ولئي أحد أشكال التشخيص التنظيمي، والذي بعتبر خطوة

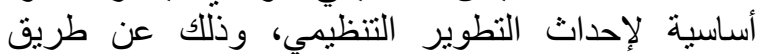
معرفة طبيعة الثقافة السائدة بغية تدعيمها أو تغييرهائها

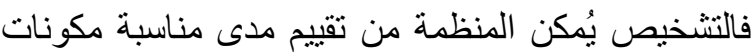

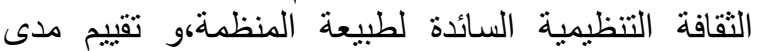
شمول وتكامل وظائف الثقافة التنظيمية، وتقبيم قابلية الثقافة التنظيمية للتأقلم مع التغير ات في البيئة الداخلية

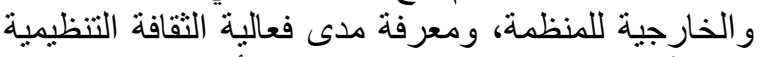

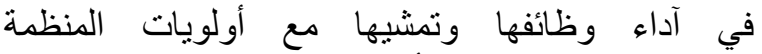
الإستراتيجية، و إكتناف أهم المعوقات الثقافية التنظيمية

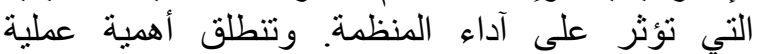
تشخيص الثقافة التنظيمية من حقيقة مؤداها بأن "ما يمكن أنساء

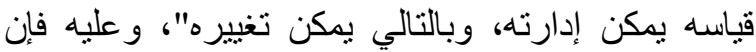

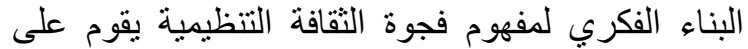
أساس قياس الثقافة التنظيمية في ضوء

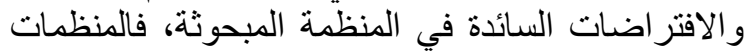

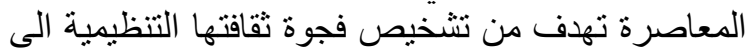
تحديد المسار المستقبلي الذي يضمن لها لها إمكانية تغيير ثقافتها التنظيمية حتى تتلاءم مع التطورات المعاري لمعاصرة.

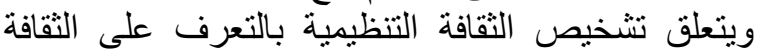
الحالية و المفضلة للمنظمة (الوضع الثقافي الحالي للمنظمة 
المنظمة مثالاً لتوجيه ور عاية العاملين وتقديم التسهيلات

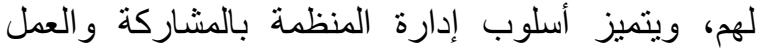

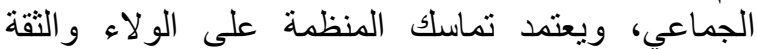

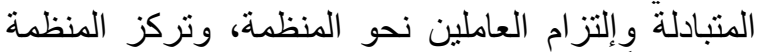

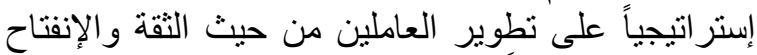

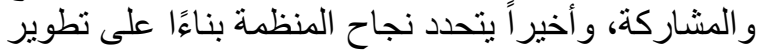
العاملين، و العمل الجماعي،و إلتزار الجم العاملين و الإستجابة لحاجاتهم ومطالبهه. The ) الثقافة الإبداعية أو ثثافة النظام المفتوح Adhocracy Culture

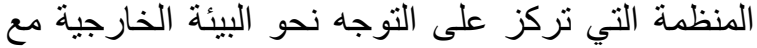

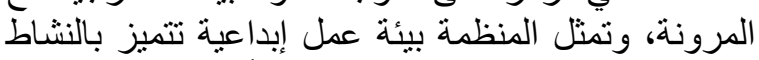

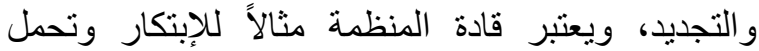

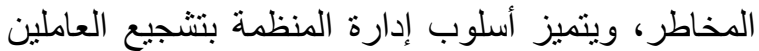

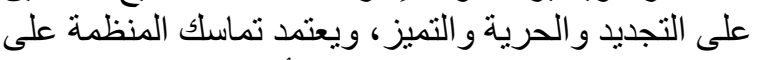

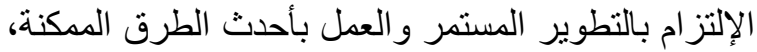
وينصب التركيز الإستر اتيجي للمنظمة على توفير موارد جديدة والبحث عن فرص وتحديات جديدة، ويتحدد نجاح الماح

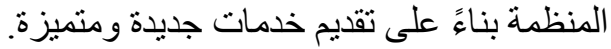
3- ثقافة السوق (The Market Culture): تصف ثقافة

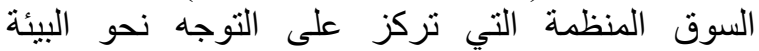
الخارجية مع الثبات و السبطرة، وتتميز بان الميز المنظمة موجهة نحو تنفيذ مهام العمل لتحقيق النتائج المطلوبة،

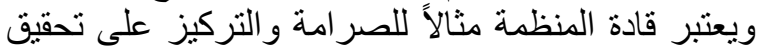

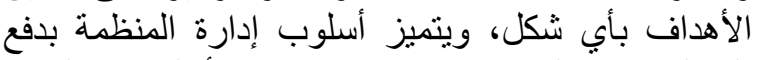
العاملين نحو المنافسة وتحقيق مستويات أعلى ألعيز من النتائج

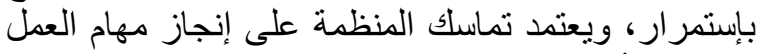

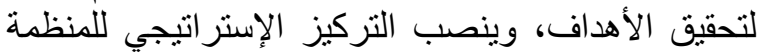
على التنافس والإنجاز وتحقيق الأهداف بعيدة المدى،

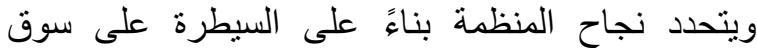
الخدمات و التقوق على الجهات المنافسة. 4- الثقافة الهرمية (The Hierarchy Culture): تشير على الفير

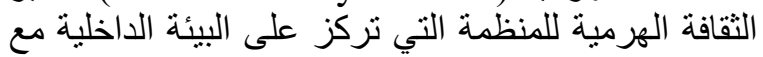

مؤشرات الفعالية التنظيمية. هذه الخلايا الأربع تتشكل

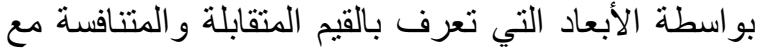
بعضها البعض، فالقيم المتعلقة بالتركيز الداخلي والفي والمرونة

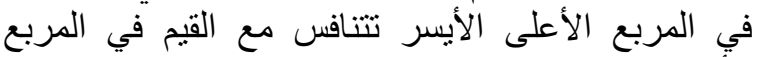

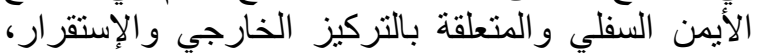

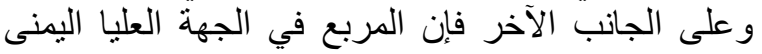

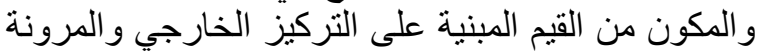

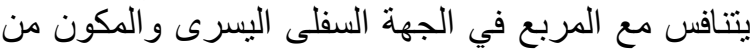

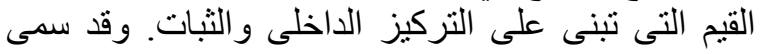
هذا النموذج بإطار القيم المتنافسة بناءً على القيم المئم المتنافسة

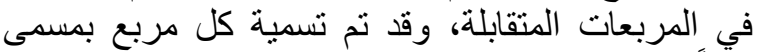

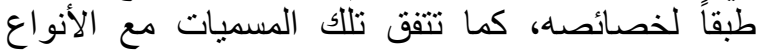

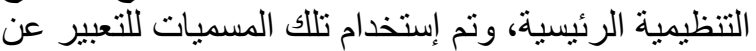

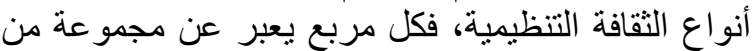

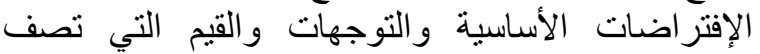
المنظمة (نفس العناصر التي تشكل الثقافة التنظيمية)، وتلك المسميات هي: ثقافة الجماعة أو القبيلة (التركيز

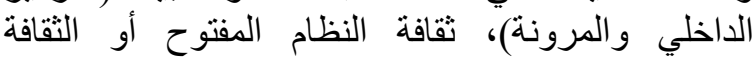
الإبداعية (التركيز الخارجي والمرونة)

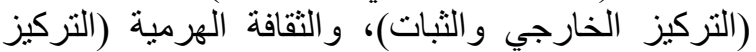
الداخلي والثبات)، وذلك كما هو موضح في شكل (1) (Cameron and Quinn, 2006; Fox, 2013; Abbink, 2015 .

وأوضح (Ameron and Quinn, 2006) الأنواع الأربعة للثقافة التنظيمية، والخصائص المميزة لكل بُعد من أبعاد الثقافة التنظيمية في كل نوع على الأفى النحو

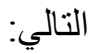

1- ثقافة الجماعة أو القبيلة (The Clan Culture): تمثل ثقافة القبيلة أو ثقافة الجماعة أونة ـ كما يفضل أن يسميها

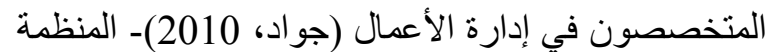

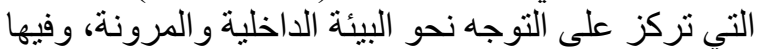
تمثل المنظمة مكان ودود للعمل يسوده المناخ الأسري

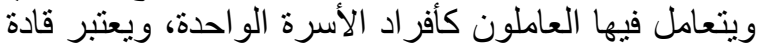

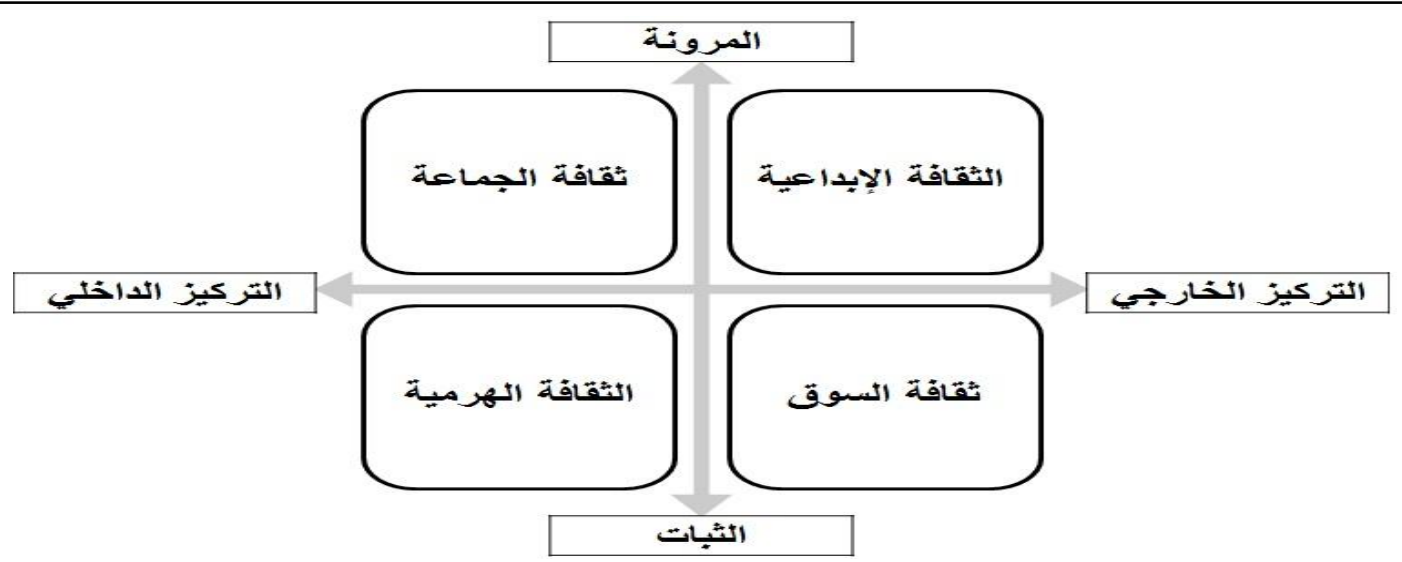

شكل (1): أنواع الثقافة التظظيمة طبقاً لإطار القيم المتنافسة

المصدر: (Cameron and Quinn, 2006) 
جدول (1): توزيع المبحوثين طبقا لخصائصهم المبينة (ن = 58).

\begin{tabular}{|c|c|c|c|}
\hline$\%$ & العدد & الخصائص & 5 \\
\hline \multicolumn{3}{|r|}{ السن } & 1 \\
\hline 20.7 & 12 & أقلل من 50 سنة & \\
\hline 79.3 & 46 & 50 سنة فأكثر & \\
\hline \multicolumn{3}{|r|}{ المؤهل الدراسى } & 2 \\
\hline 56.9 & 33 & دبلوم & \\
\hline 43.1 & 25 & بكالوريوس & \\
\hline \multicolumn{3}{|r|}{ الوظيفة } & 3 \\
\hline 70.7 & 41 & أخصائى & \\
\hline 29.3 & 17 & مسئول المركز & \\
\hline \multicolumn{3}{|c|}{ مدة العمل بالمركز الإرشادى } & 4 \\
\hline 36.2 & 21 & أقل من 10 سنو ات & \\
\hline 63.8 & 37 & 10 سنو ات فأكثر & \\
\hline
\end{tabular}

كانت أعمار هم من 50 سنة فأكثر (56,9\%) (79,3)، ومن ذوي

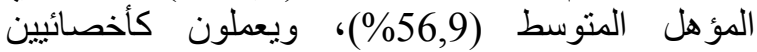

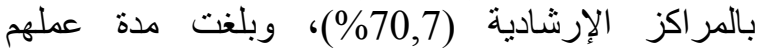
بالمر اكز الإرشادية 10 سنوات أو أكثر (63,8\%).

ثانياً: أنواع الثقافة التنظيمية الحالية والمرغوبة والفجوة الترئة

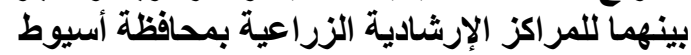

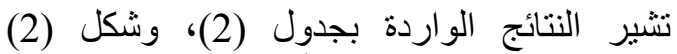
والمتعلقة بإدراكات المبحوثين لأنواع الثباع الثقافة التنظيمية

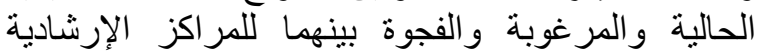

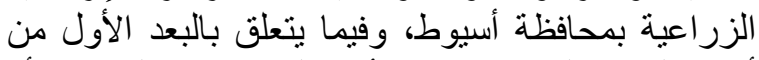

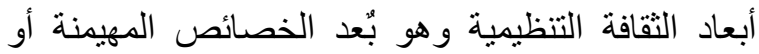

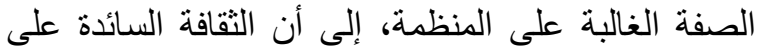

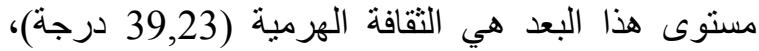
تليها على الترتيب ثقافة السوق (27,83 درجة) وثقافة التية الجماعة (21,03 درجة)، وأخيراً الثقافة الإبداعية

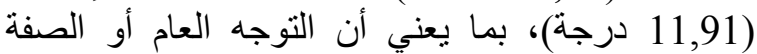

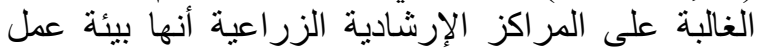

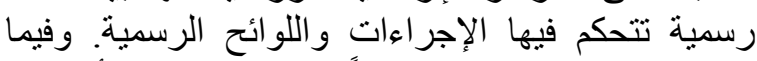

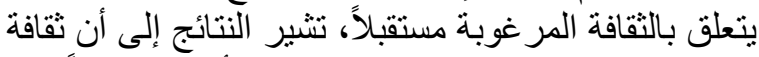
الجماعة (34,91 درجة) هي الثقافة الأكثر تفضيلاً بين

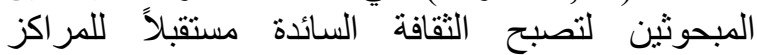

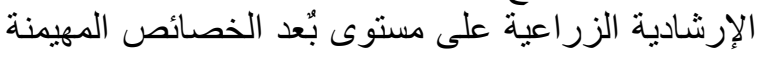
بزيادة قدر ها (13,88 درجة) عن الثقائة الثقافة التنظيمية الحالية،

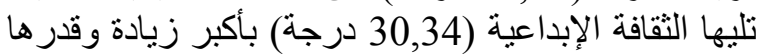

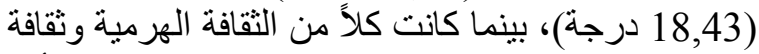
السوق (14,83، 19,92 درجة بندة على بلى الترتيب) الأقل

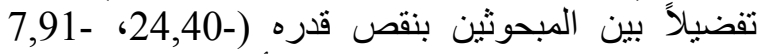
درجة على الترتيب). ويشير ذلك اللكئ إلى أن العاملين بالمر اكز

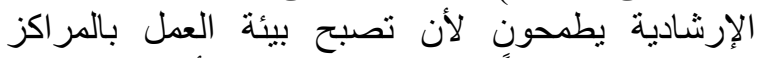

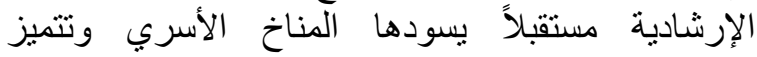

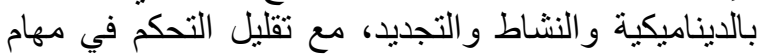

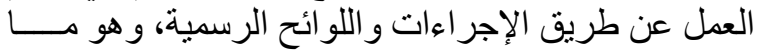

الثبات و السيطرة، وتمثل المنظمة بيئة عمل رسمية تتحكم

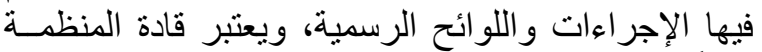

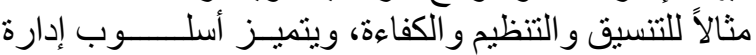

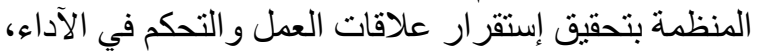

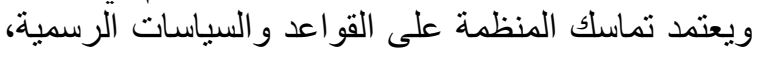

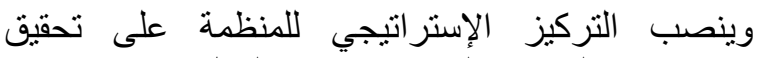

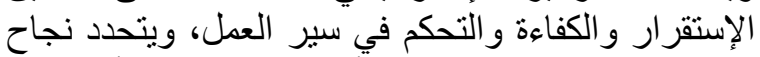

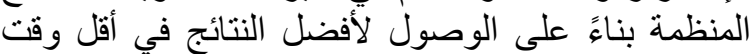

$$
\text { 3- طريقة إجراء البحث }
$$

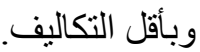

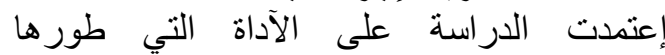

لتشخيص الثقافة (Cameron and Quinn, 2006) التنظيمية وفق تصنيف إطار القيم المتنافسة. وقد صمدت

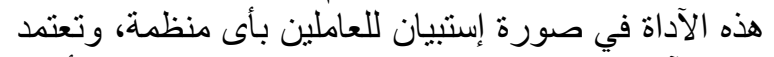

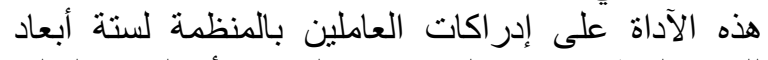

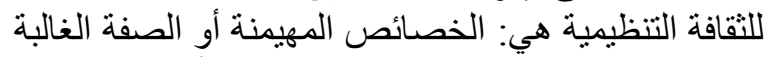

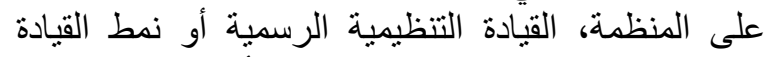

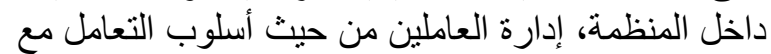

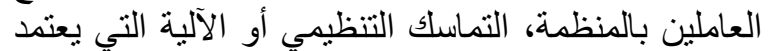

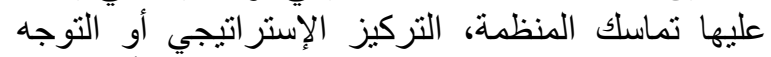

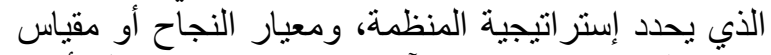

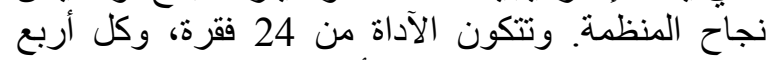
فقر ات (بدائل) موز عة على الأبعاد الستة للثقافة التنظيمية التانة

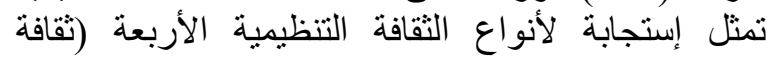

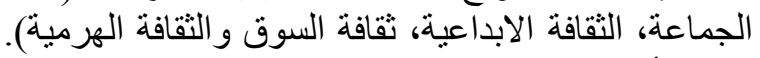

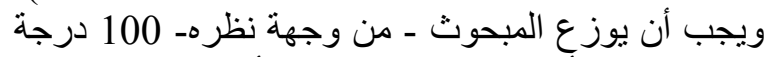

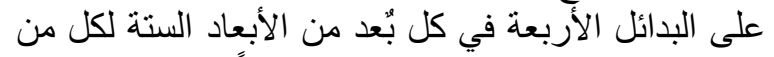

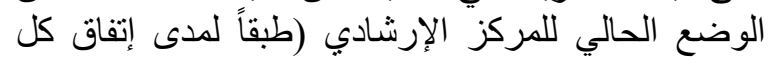

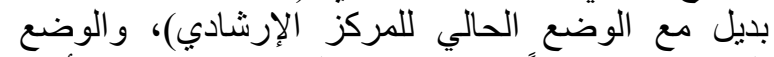

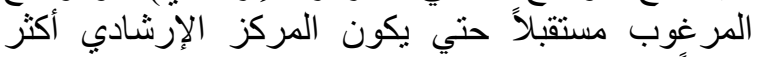

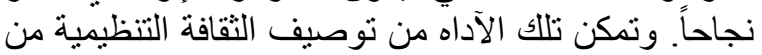
حيث نوع وقوة الثقافة التنظيمية، فجوة الاذبة الثقافة التنظيمية

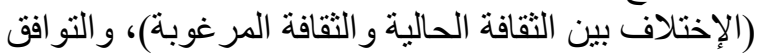

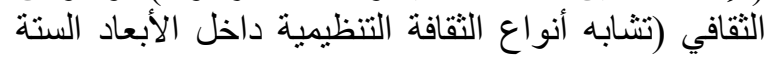

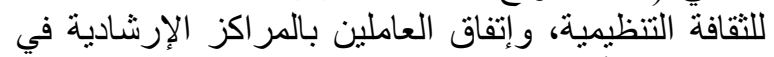

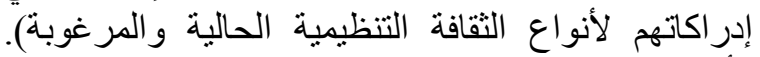

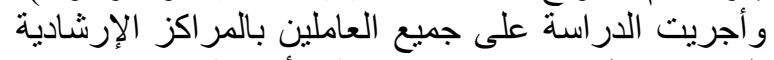
الزراعية السبعة عشر بمحافظة أسيوط وعائة وعددهم 58 مبحوثاً، وتم جمع البيانات بإستخدام إستمارة الإستبيان

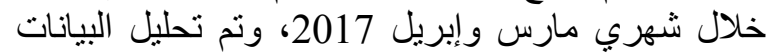

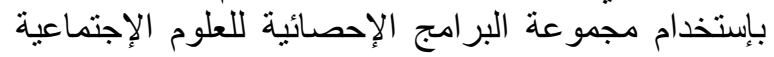

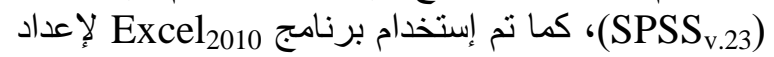

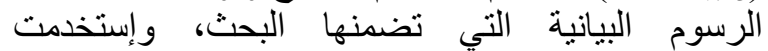
التكرارات والنسب المئوية والمتوسط الحسابي لعرض إلنغ

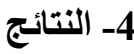

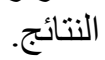
أولاً: خصائص المبحوثين

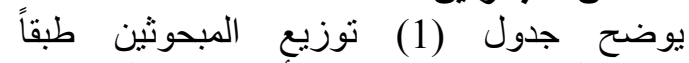
لخصائصهم المبينة، ومنه يلاحظ أن معظم المبحوثين 
المراكز الإرشادية (مسئولي المراكز الإرشادية بالقرى، الزئل

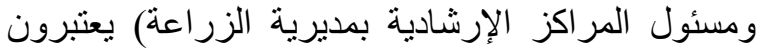

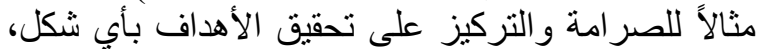

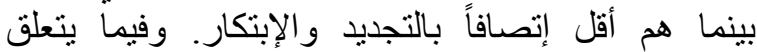
بالثقافة المرغوبة مستقبلاً، تثير النتائج إلى أنى أن نقافئة الجماعة (36,21 درجة) هي الثقافة الأكثر تفضيلاً بين

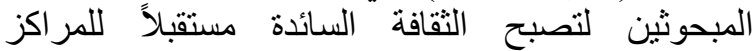
الإرشادية الزراعية على مستوى بُّعد القيادة التنظيمية التئية

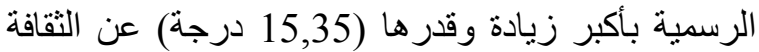

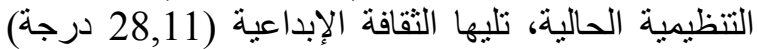
بزيادة قدر ها (12,42 درجة) ، بينما كانت كلاً من ثقافة

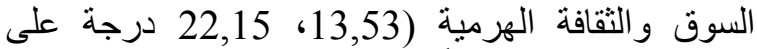

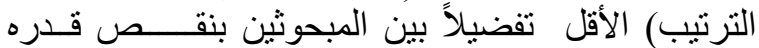

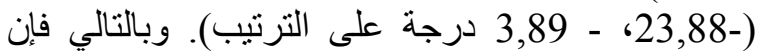
فجوة الثقافة التنظيمية على مستوى بُّعد القيادة التنظيمية

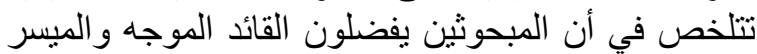

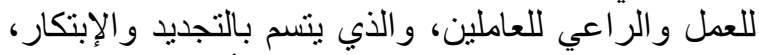

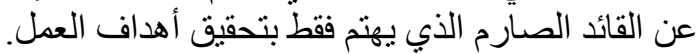

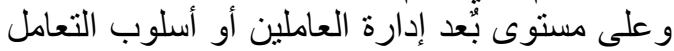

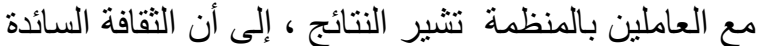

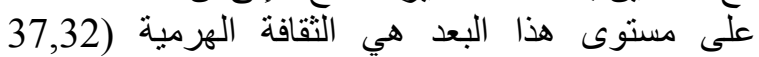
درجة)، تليها على الترتيب ثقافة السوق (28,11 درجة) وثقافة الجماعة (18,88 درجة)، والخية وأخيراً الثقافة الإبداعية

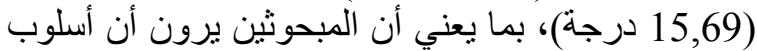

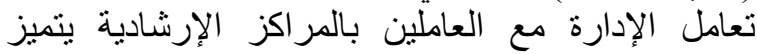

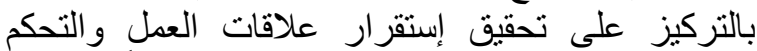

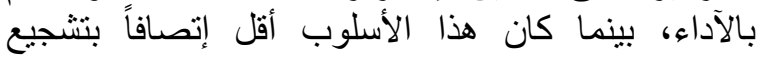
العاملين على التجديد و الحرية و التميز. و وفيما يتعلق بالثقافة التئة

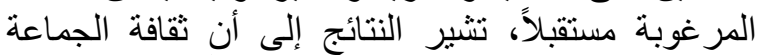

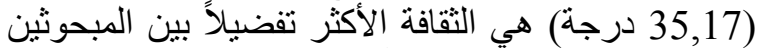

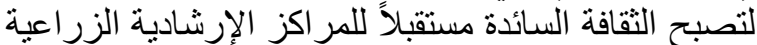
على مستوى بُعد إدارة العاملين بأكبر زيادة الإن وقادية الزراعها

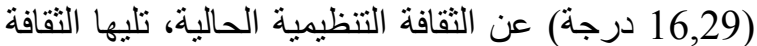
الإبداعية (31,03 درجة) بزيادة قدر ها (15,34 درجة (لرجة)،

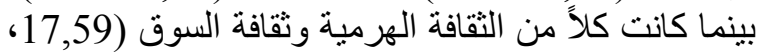

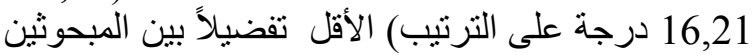
بنقص قدره (-19,73، - 11,90 درجة على الإنى الترتيب). أى الى

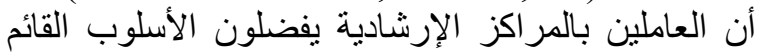

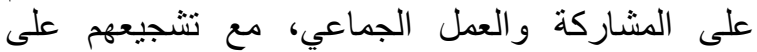

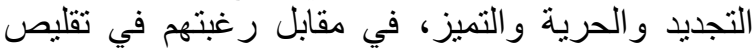
أسلوب التعامل القائم على الإكتفاء بمجرد تحابل تحقيق إستقرار علاقات العمل و التحكم بالآداء. وتبين النتائج الواردة بنفس الجدول على مستوى بُّعد التماسك التنظيمي، أن الثقافة السائدة على مستوى هذا لنفا البعد

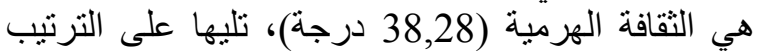
ثقافة السوق (30,43 درجة) وثقافة الجماعة (16,38

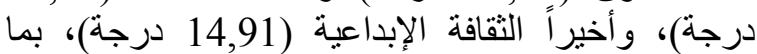

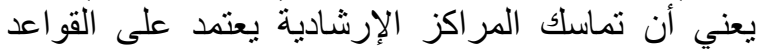

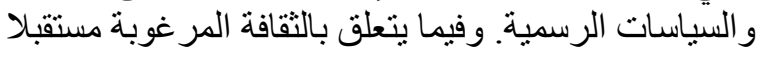

جلول (2):المتوسطات الحسابية لإدراكات المبحوثين لأنواع الثقافة التنظيمية الحالية والمرغواتية المبية والفجوة بينهما للمراكز الإرشادية الزراعية ولية النية

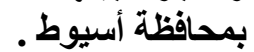

\begin{tabular}{|c|c|c|c|}
\hline $\begin{array}{c}\text { (الفجوة) } \\
\end{array}$ & المرغوبة & الحالية & أنواع وأبعاد الثقافة \\
\hline \multicolumn{4}{|r|}{ الخصائص المهيمنة } \\
\hline 13,88 & 34,91 & 21,03 & ثقافة الجماعة \\
\hline 18,43 & 30,34 & 11,91 & الثقافة الإبداعية \\
\hline $7,91-$ & 19,92 & 27,83 & ثُقافة السوق \\
\hline $24,40-$ & 14,83 & 39,23 & الثقافة الهرمية \\
\hline \multicolumn{4}{|r|}{ القيادة التنظيمية } \\
\hline 15,35 & 36,21 & 20,86 & ثُقافة الجماعة \\
\hline 12,42 & 28,11 & 15,69 & الثقافة الإبداعية \\
\hline $23,88-$ & 13,53 & 37,41 & ثُقافة السوق \\
\hline $3,89-$ & 22,15 & 26,04 & الثقافة الهرمية \\
\hline \multicolumn{4}{|r|}{ إدارة العاملين } \\
\hline 16,29 & 35,17 & 18,88 & ثُقافة الجماعة \\
\hline 15,34 & 31,03 & 15,69 & الثقافة الإبداعية \\
\hline $11,90-$ & 16,21 & 28,11 & ثُقافة السوق \\
\hline $19,73-$ & 17,59 & 37,32 & الثقافة الهرمية \\
\hline \multicolumn{4}{|r|}{ التماسكك التنظيمي } \\
\hline 19,91 & 36,29 & 16,38 & ثقافة الجماعة \\
\hline 10,95 & 25,86 & 14,91 & الثقافة الإبداعية \\
\hline $8,62-$ & 21,81 & 30,43 & ثُقافة السوق \\
\hline $22,24-$ & 16,04 & 38,28 & الثقافة الهرمية \\
\hline \multicolumn{4}{|r|}{ التركيز الإستراتيجي } \\
\hline 19,57 & 38,28 & 18,71 & ثقافة الجماعة \\
\hline 8,36 & 27,58 & 19,22 & الثقافة الإبداعية \\
\hline $10,69-$ & 15,95 & 26,64 & ثقافة السوق \\
\hline $17,24-$ & 18,19 & 35,43 & الثقافة الهرمية \\
\hline \multicolumn{4}{|r|}{ معيار النجاح } \\
\hline 20,69 & 39,14 & 18,45 & ثقافة الجماعة \\
\hline 4,22 & 24,05 & 19,83 & الثقافة الإبداعية \\
\hline $5,28-$ & 17,39 & 22,67 & ثقافة السوق \\
\hline $19,63-$ & 19,42 & 39,05 & الثقافة الهرمية \\
\hline \multicolumn{4}{|r|}{ جميع الأبعاد } \\
\hline 17,62 & 36,67 & 19,05 & ثُقافة الجماعة \\
\hline 11,62 & 27,83 & 16,21 & الثقافة الإبداعية \\
\hline $11,39-$ & 17,46 & 28,85 & ثقافة السوق \\
\hline $17,85-$ & 18,04 & 35,89 & الثقافة الهرمية \\
\hline
\end{tabular}

يلخص فجوة الثقافة التنظيمية على مستوى بُّحد الخصائص المهيمنة.

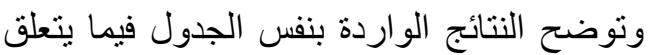

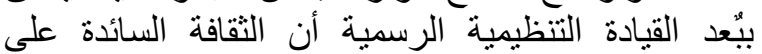

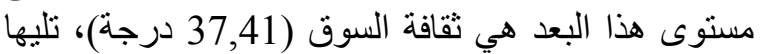

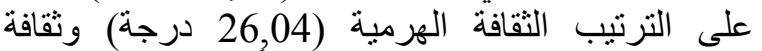
الجماعة (20,86 درجة)، والخية أخيراً الثقافة الإبداعية (15,69 درجة)، بما يعني أن المبحوثين يرون أن قادة الإباءة 


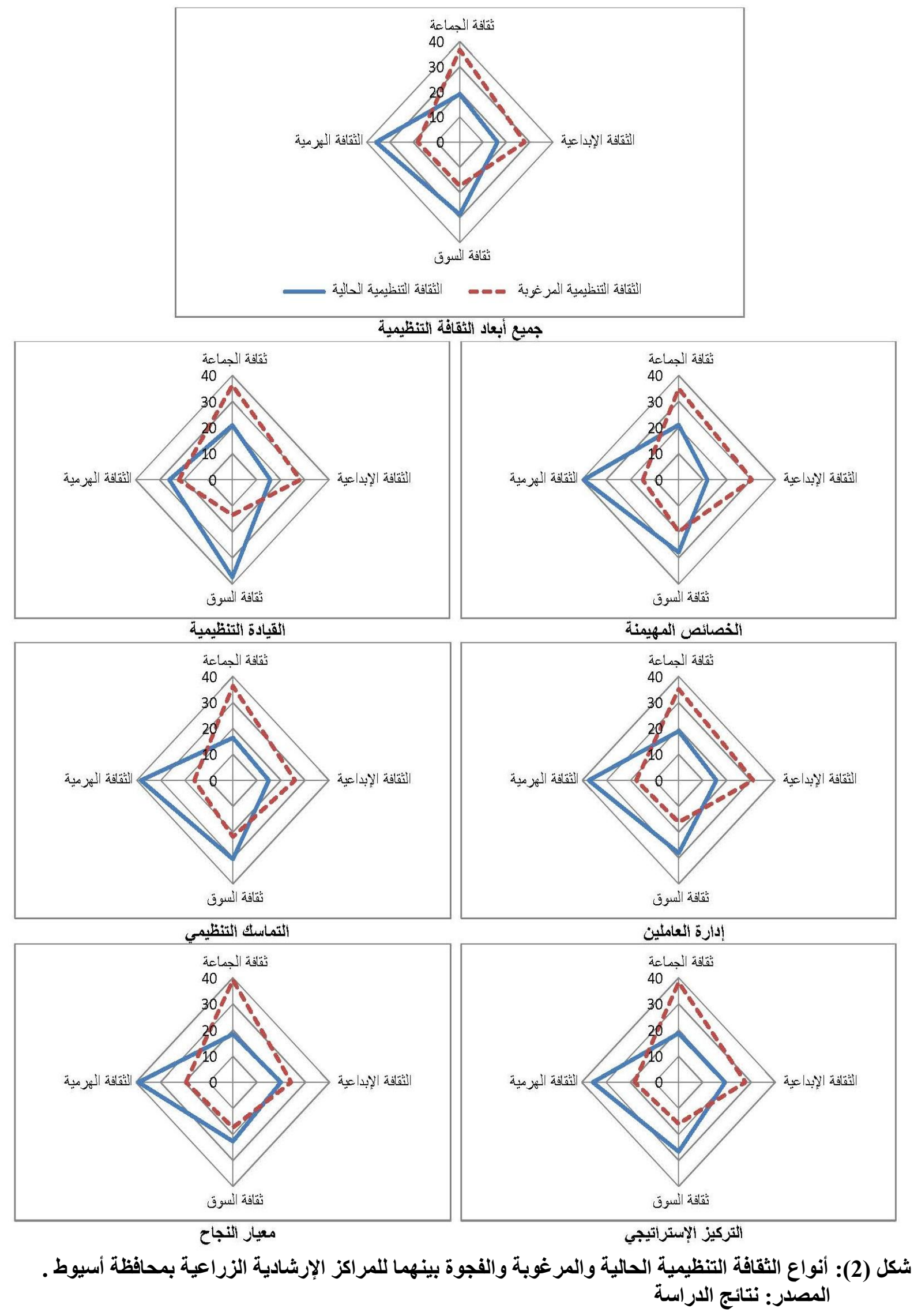


قدرها (20,69 درجة) عن الثقافة التنظيمية الحالية، تليها

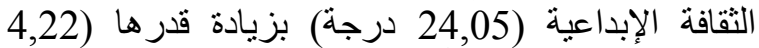
درجة) ، بينما كانت كلاً من الثقافة الهرمية وتثقافة السوق (19,42، 17,39 درجة على الترنيب) الأقل تفضيلاً بين

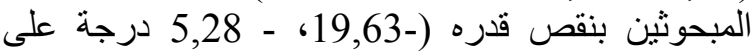
الترتيب). وبالتالي تتضح رغبة رثبة المبحوثين في أن يتحدد

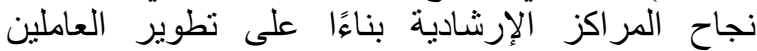

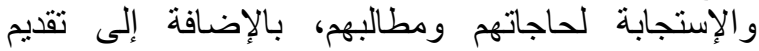

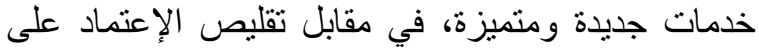

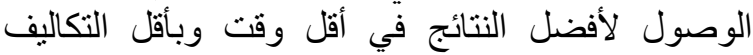
كمعيار لنجاح المر اكز الإرشادية الزراعية. وبعد إستعر اض أنواع الإدادية النقافة التنظيمية الحالية

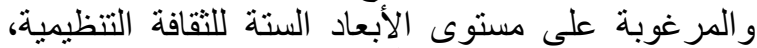

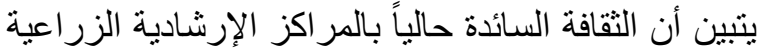

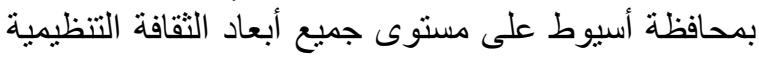

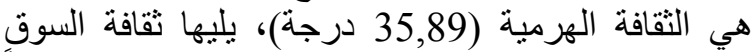

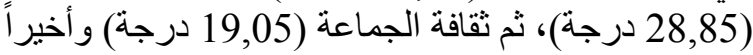
الثقافة الإبداعية (16,21 درجة). وتتميز الثية الثقافة الهرمية والثية السائدة بالقوة، حيث أن الفرق بينها وبين الثقافة الإبداعية

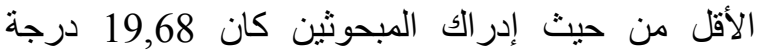
(أكبر 10 درجات) بما يعني أن عملية تغيير الثقافة الهرمية الثية دونية السائدة ليست سهلة وتتطلب وقت ونت وجهد أكبر .(OCAI online, 2012; Karsters, 2011) أما عن النقافة المرغوبة مستقبلاً، توضح النتائج أن ثقافة

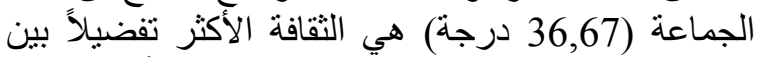

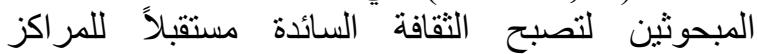
الإرشادية الزراعية بزيادة قدرها (17,62 درجة) عن الإنة الإنة

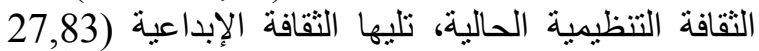
درجة) بزيادة قدرها (11,62 درجة)، بينة النما كانت كلاً من الأنة

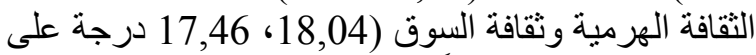

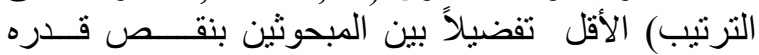

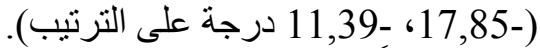
وطبقاً للقاعدة التي تنص على أن الفرق الأكبر من التن

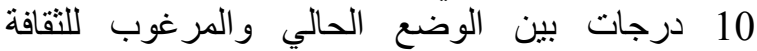

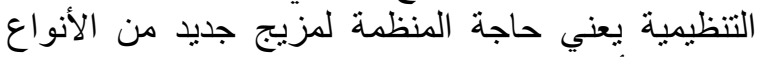

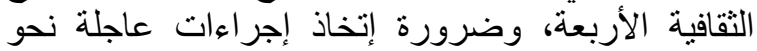
تعديل الثقافة التنظيمية في الإتجاه الذي ير غبه العاملون بها التها (OCAI online, 2012; Abbink, 2015) القاعدة تنطبق على المراكز الإرشادية الزراعية المبان

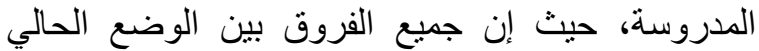

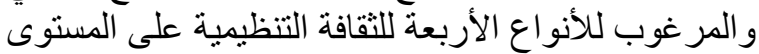

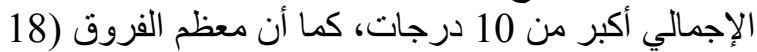

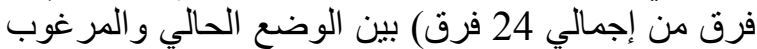
للأنواع الثقافية الأربعة داخل أبعاد الثقافة التنظيمية الستة أكبر من 10 درجات.

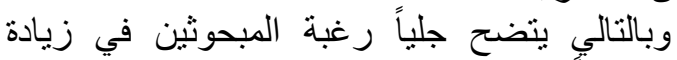

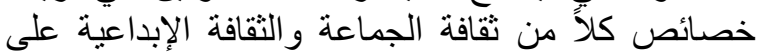
المستوى الإجمالي لجميع أبعاد الثقافة التنظيمية، في مقابل التهابل تقليص خصائص كلاً من ثقافة السوق والثقافة التئة الترمية،
تشير النتائج إلى أن ثقافة الجماعة (36,29 درجة) هي التئ

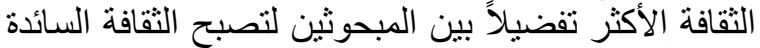

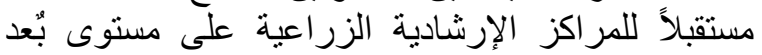

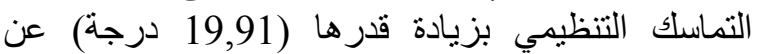

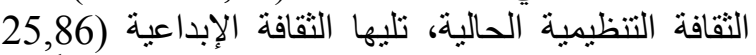

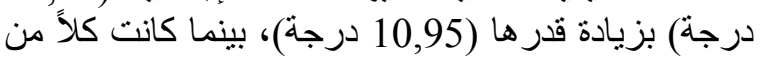
الثقافة الهرمية وثقافة السوق (16,04،

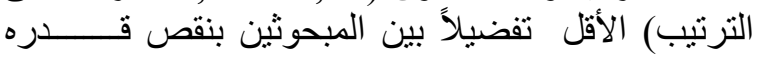

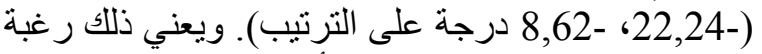

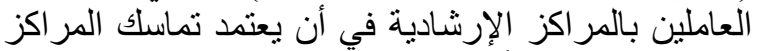

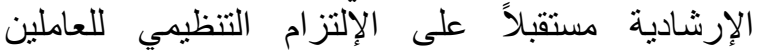

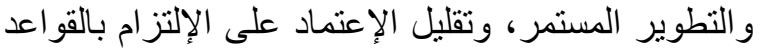

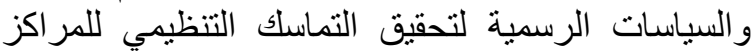

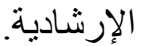

ومن حيث بُعد التركيز الإستراتيجي، تشير النتائج

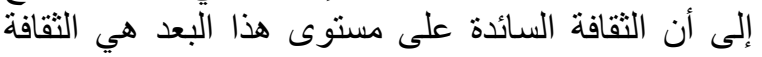

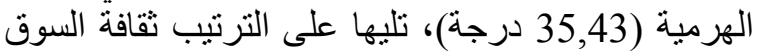

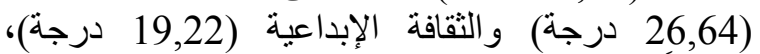

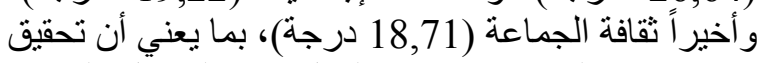

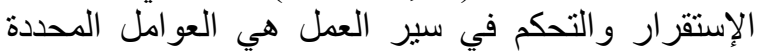

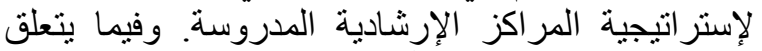

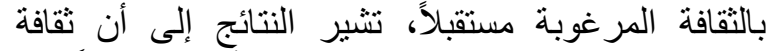
الجماعة (38,28 درجة) هي الثقافة الأكثر تفضيلاً بين

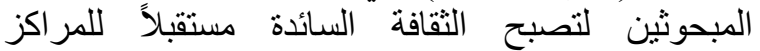
الإرشادية الزر اعية على مستوى بُّعد التركيز الإستر اتيجي

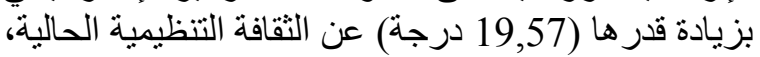

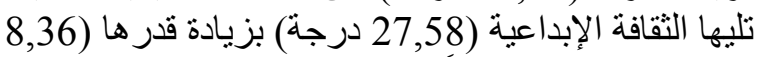

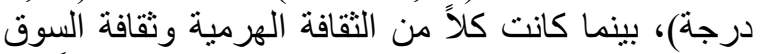

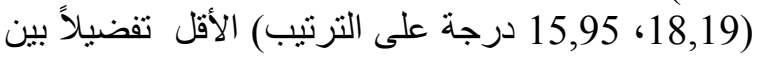

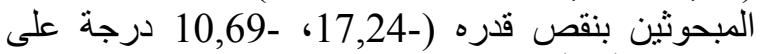

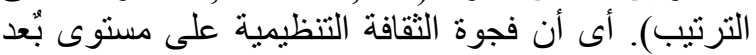
التركيز الإستراتيجي تتمثل في أن إسترة التئية التيجية المنظمة

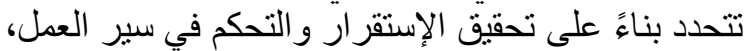

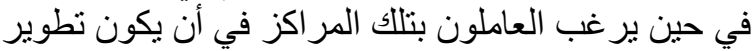

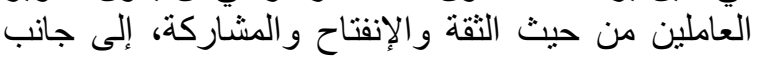

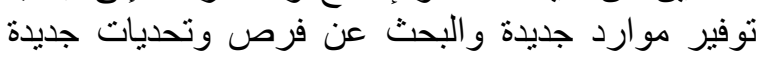

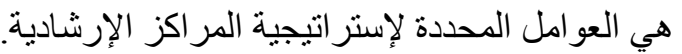

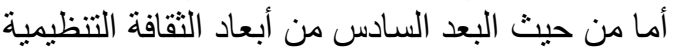

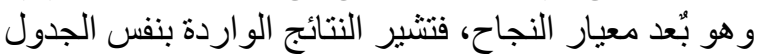

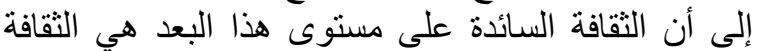

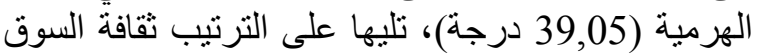
(22,67 درجة) و الثقافة الإبداعية (19,83 (19,45 درجة)،

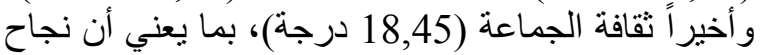

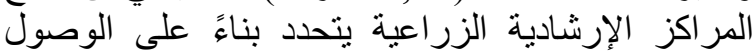

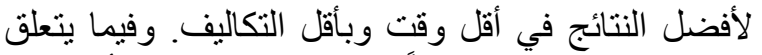

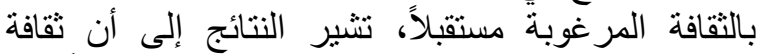

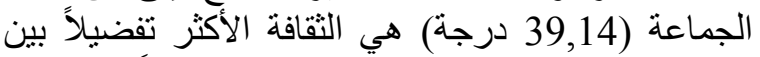

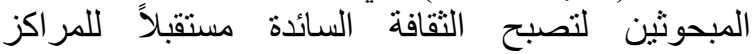

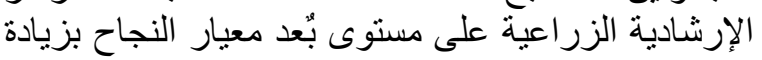


(OCAI online,2012; الثقافي للمنظمة و العكس صحيح ) فئح (Abbink, 2015 فإن نتائج الدراسة الحالية تعكس الإنة التوافق الثقافي للمراكز الإرشادية المدروسة، حيث إن إن الن النية الغالبية العظمى من الفروق (22 فرق من الإنية إنمالي 24

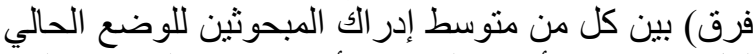

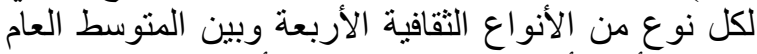

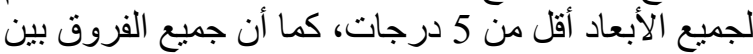

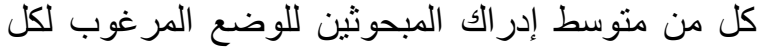

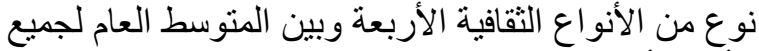

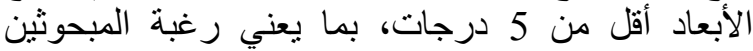
المستقبلية في تطابق الأنواع الثقافية داخل أبعاد الثقافة التنظيمية. و على الجانب الآخر للتو افق الثقافي داخل المراكز

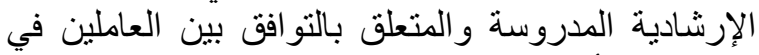

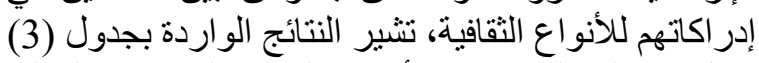

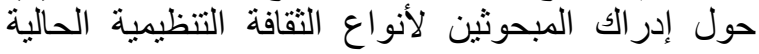

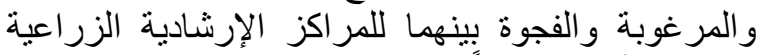

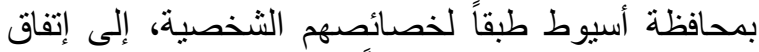

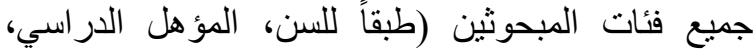

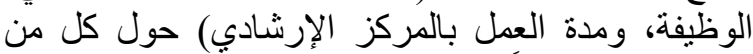

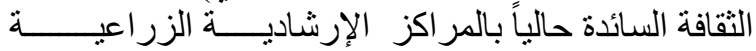

بما يعني رغبة المبحوثين في مزيد من المرونة والحرية

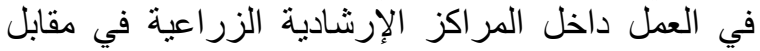
تقليص الرسمية والثبات والتحكم، مع إستمرار التمارية التركيز

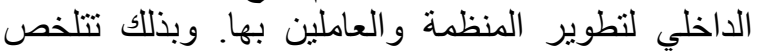

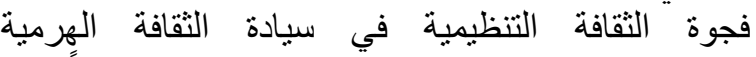
البيروقر اطية داخل المر اكز الإرشادية الزر اعية حالياً، في في الجية

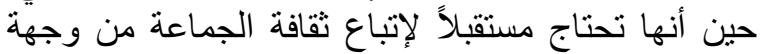
نظر العاملين بتلك المر اكز.

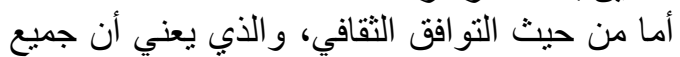

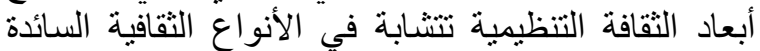
بها، كما يشمل التو افق بين العاملين بالمنظمة في إدراعة اكاتهم

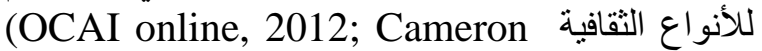

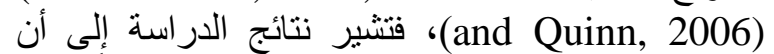
هناك إتفاق بين المبحوثين على الثقافة السائدة حالياً داخل

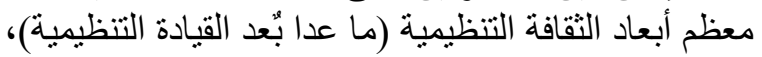

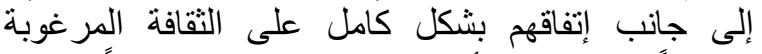

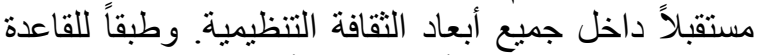

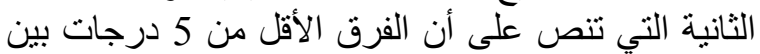

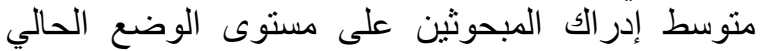
أو المرغوبط لكل نوع من الأنواع الثقافية الأربعة وبين التوبن

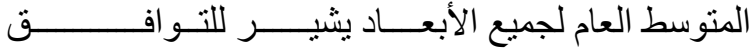

جدول (3): المتوسطات الحسابية لإدراكات المبحوثين لأنواع الثقافة التنظيمية الحالية والمرغوبة والفجوة بينهما

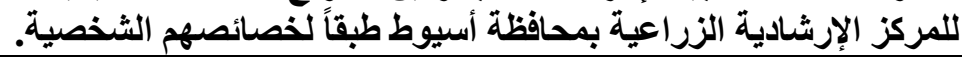

\begin{tabular}{|c|c|c|c|c|c|c|c|c|}
\hline \multicolumn{2}{|c|}{ مدة العمل بالمركز } & \multicolumn{2}{|c|}{ الوظيفة } & \multicolumn{2}{|c|}{ المؤهل الاراسي } & \multicolumn{2}{|c|}{ السن } & \multirow{2}{*}{ أنواع الثقافة } \\
\hline 10 فنأكثرات & 10 أقل من 10 & أخصائي & المركز & بكالوريوس & دبلوم & فأكثر 50 سنة & أقل منة 50 & \\
\hline \multicolumn{9}{|r|}{ ثقافة } \\
\hline 19,23 & 18,88 & 18,78 & 19,31 & 19,97 & 18,16 & 18,95 & 19,14 & الثقافة الحالية \\
\hline 37,59 & 35,75 & 35,63 & 37,69 & 37,53 & 35,81 & 36,56 & 36,78 & الثقافة المرغوبة \\
\hline 18,36 & 16,87 & 16,85 & 18,38 & 17,56 & 17,65 & 17,61 & 17,64 & الفرق (الفجوة) \\
\hline \multicolumn{9}{|r|}{ الثقافة الإبداعية } \\
\hline 16,17 & 16,22 & 16,41 & 16,02 & 16,40 & 15,98 & 16,43 & 15,98 & الثقافة الحالية \\
\hline 26,47 & 29,18 & 28,72 & 26,91 & 27,17 & 28,49 & 27,83 & 27,85 & الثقافة المرغوبة \\
\hline 10,30 & 12,96 & 12,31 & 10,89 & 10,77 & 12,51 & 11,40 & 11,87 & الفرق (الفجوة) \\
\hline \multicolumn{9}{|r|}{ ثقافة السوق } \\
\hline 28,58 & 29,11 & 29,02 & 28,69 & 27,26 & 30,43 & 29,04 & 28,69 & الثقافة الحالية \\
\hline 17,03 & 17,88 & 17,61 & 17,29 & 17,13 & 17,78 & 17,39 & 17,52 & الثقافة المرغوبة \\
\hline $11,55-$ & $11,23-$ & $11,41-$ & $11,40-$ & $10,13-$ & $12,65-$ & $11,65-$ & $11,17-$ & الفرق (الفجوة) \\
\hline \multicolumn{9}{|r|}{ الثقافة الهرمية } \\
\hline 36,02 & 35,79 & 35,79 & 35,98 & 36,37 & 35,43 & 35,58 & 36,19 & الثقافة الحالية \\
\hline 18,91 & 17,19 & 18,04 & 18,11 & 18,17 & 17,92 & 18,22 & 17,85 & الثقافة المرغوبة \\
\hline $17,11-$ & $18,60-$ & $17,75-$ & $17,87-$ & $18,20-$ & $17,51-$ & $17,36-$ & $18,34-$ & الفرق (الفجوة) \\
\hline
\end{tabular}




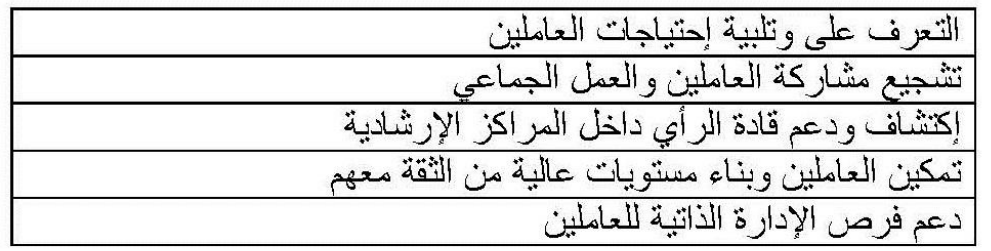

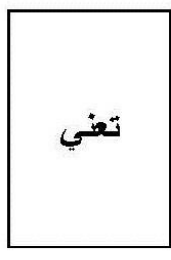

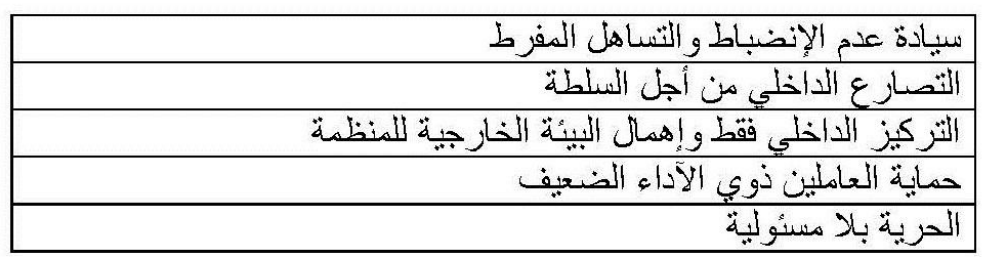

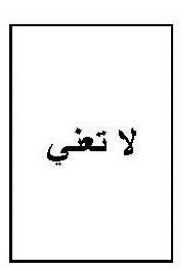

زيادة خصائص ثقافة الجماعة

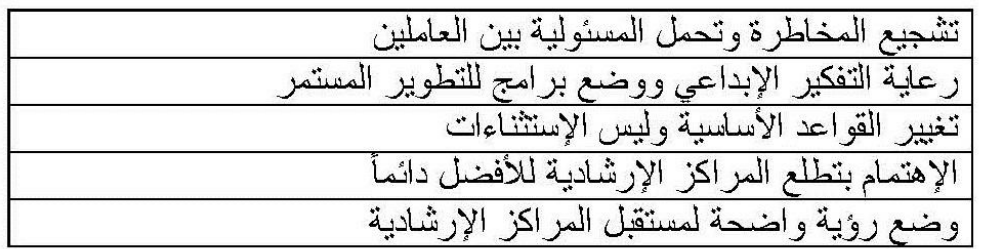

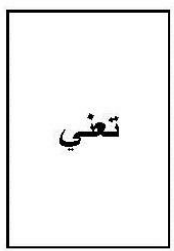

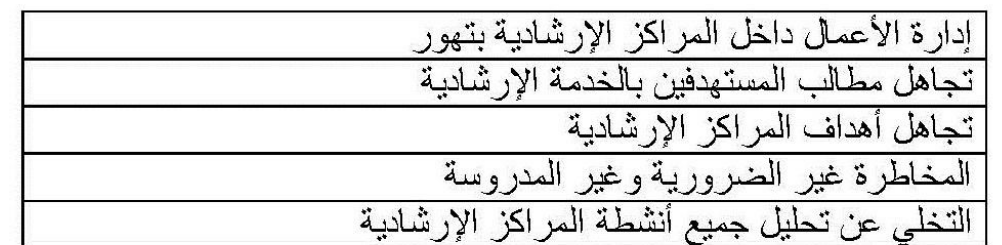
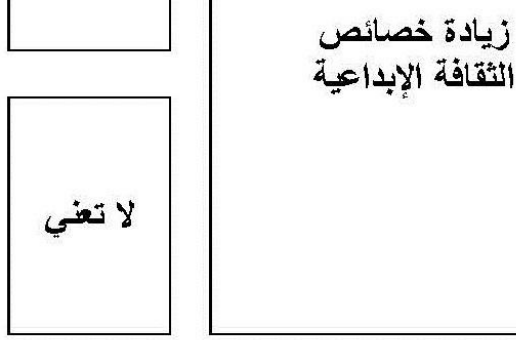

الثقافة الإبداعية خصائة

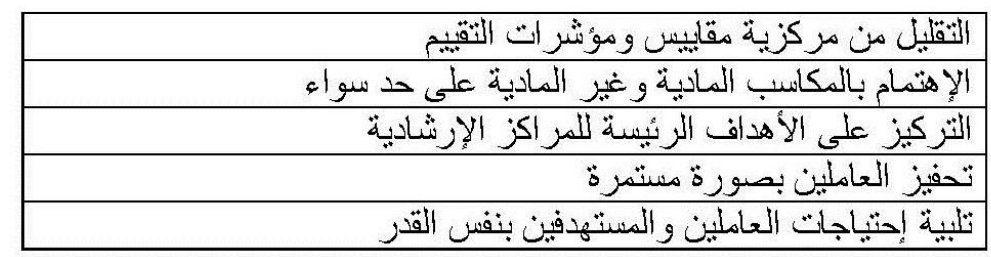

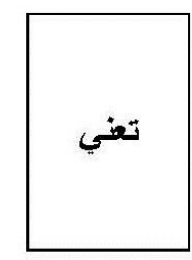

\begin{tabular}{|c|c|}
\hline & تجاهل المنافسة مع الجهات التي تقدم خدمات مشابهة \\
\hline & فقدان الر غبة في تققيم أفضل الَّدمات دائُاً \\
\hline & إهمال الأهداف طويلة المدى \\
\hline & تجاهل الميز انيات بشكل كامل \\
\hline & التت قف عن تقبيم التتائج بصورة مستمرة \\
\hline
\end{tabular}
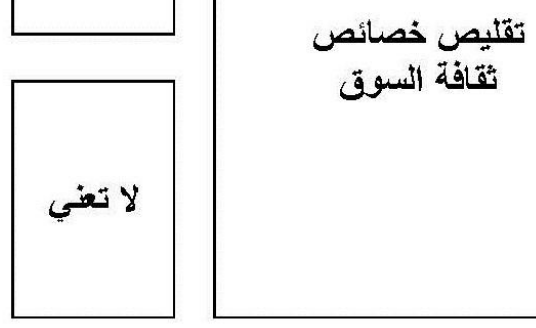

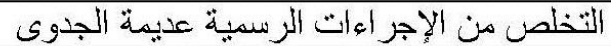

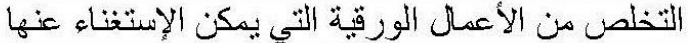

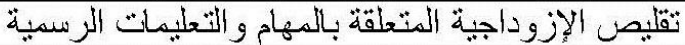

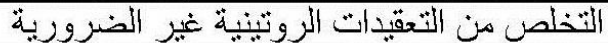

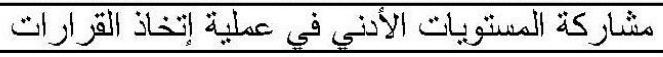

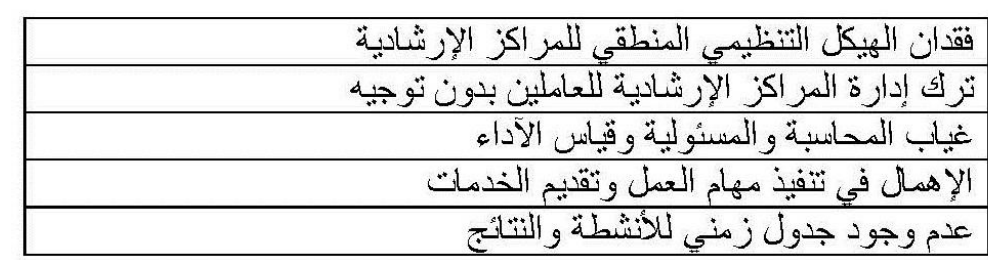
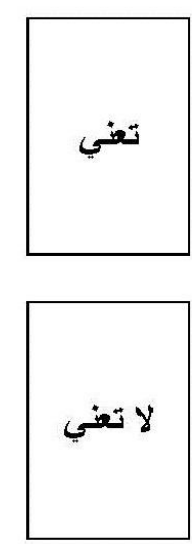

تقليص خصائص التصري الأثقافة الثهرمية خصانة

شكل(3): الإعتبرات التي يجب مراعاتها عند تغيير الثقافة التنظيمية للمراكز الإشادية الزراعية بححافظة أسيوط في صورة ما يعنيه أولا يعنيه زيادة أو نقص خصائص أنواع الثقافة التنظيمية . المصدر: مستخلص من (Cameron and Quinn, 2011) بناءً على نتائج الدراسة الحالية 
OCAI online, العاملين بها في فترة زمنية معينة 2012

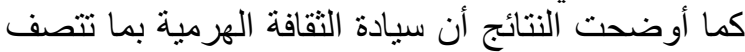

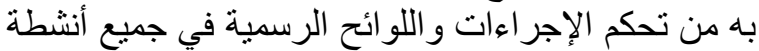

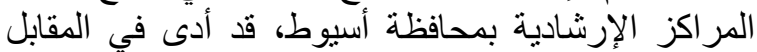

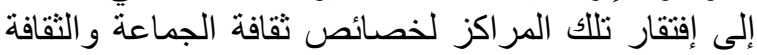

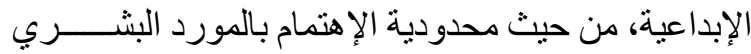

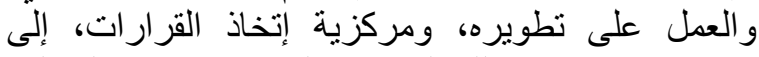
جانب عدم إتصاف تللك المر اكز بالتجديد وتشجيع العاملين على التفكير المبدع. و أشارت النتائج إلى رغبة المبحوثين في أن تحتوي

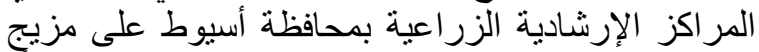

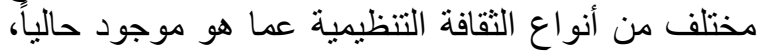

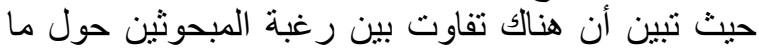

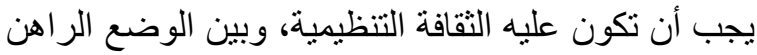

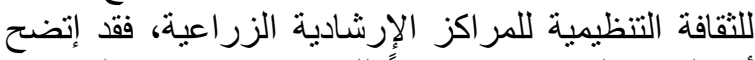

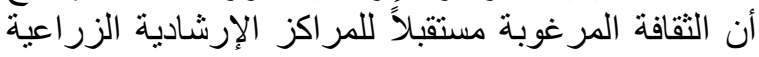

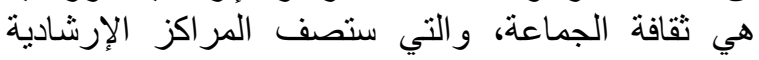
الزراعية كمنظمة نركز على التوجه لتهية نحو البيئة الداخلية

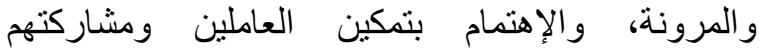

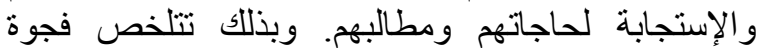

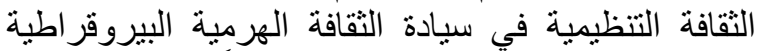
داخل المراكز الإرشادية الزراعية حالياً، في حين أنها لإنا

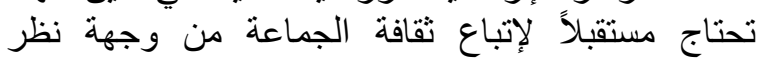
العاملين بتلك المر اكز.

كما بينت النتائج إتصاف الثقافة التنظيمية الحالية

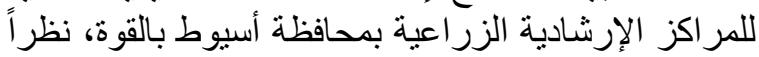

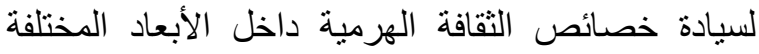

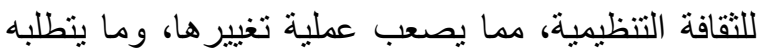
ذلك التغيير من وقت أطول وجهة أكبر. كما تتصف التهان الثقافة التنظيمية بالتوافق الثقافي، أي تثابه الأنواع الثئ الثقافية السائدة

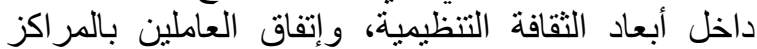

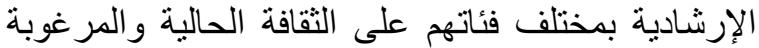
داخل جميع أبعاد الثقافة التنظيمية.

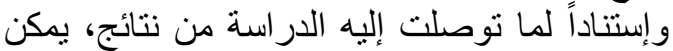

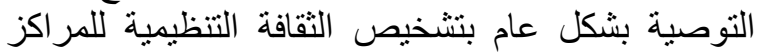

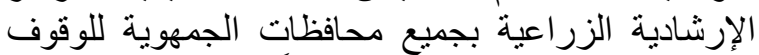

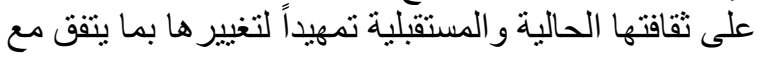

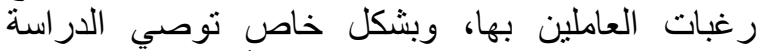

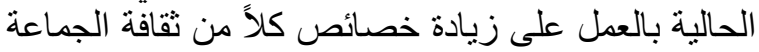

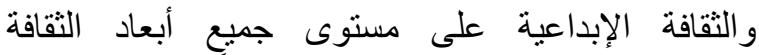

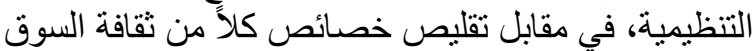

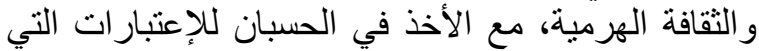

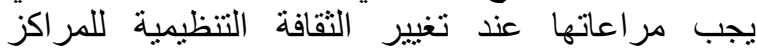

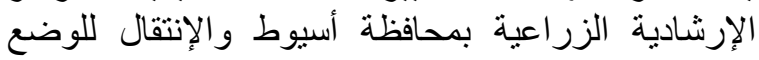

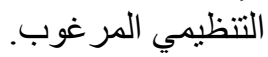

بمحافظة أسيوط (الثقافة الهرمية)، و الثقافة المرغوبة

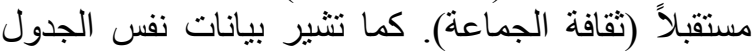

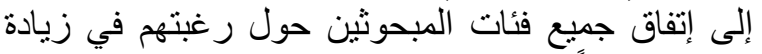
خصائص كلاً من ثقافة الجماعة و الثقافة الإبداعية (يتضح

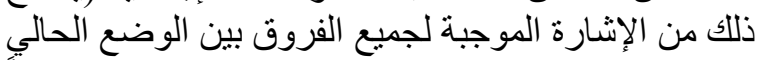

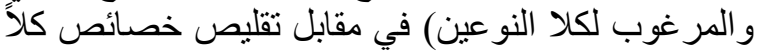

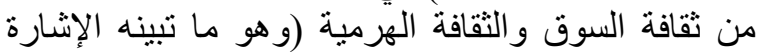

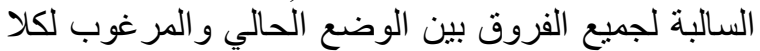

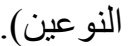

ثُالثاً: الإعتبارات التي يجب مراعاتها عند تغيير الثقافة التنظيمية للمراكز الإرشادية الزراعية التية بمحافظة

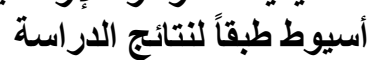

ذكر Fox (2013) أنه لفهم نتائج تطبيق آداة

تشخيص الثقافة التنظيمية، يجب معرفة ما يعنية أو لا يعنية آنية

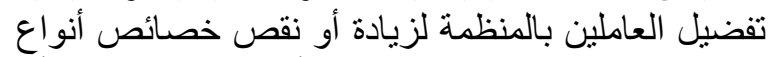

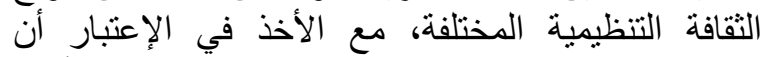

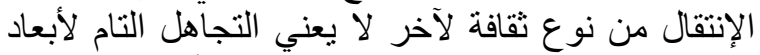
ذللك النوع الآخر، ولكن ذللك يعني التركيز أو عدم التركيز

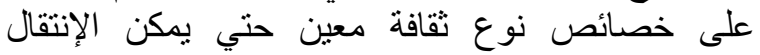

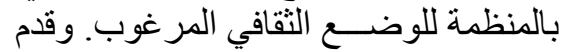
(Cameron and Quinn, 2011) تطبيق آداة تشخيص الثقافة التنظيمية من حيث ما يعنيه أو لون لا يعنيه تغيير الثقافة التنظيمية لأي منظمة في إتجاه زيادة

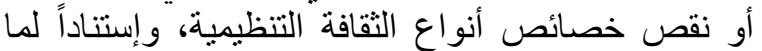

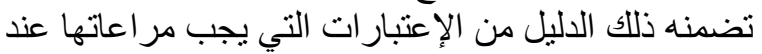
تغيير الثقافة التنظيمية لأي منظمة عقب الإبل إستخدام آداة

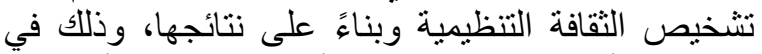

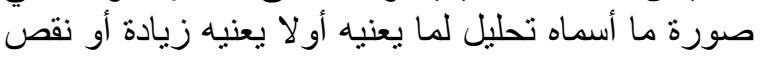

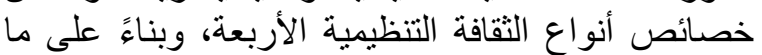

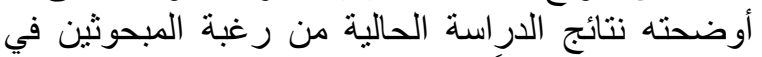
زيادة خصائص كلاً من ثقافة الجماعة و الثقافة الإبداعية،

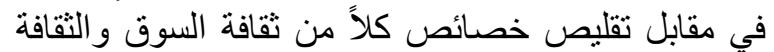

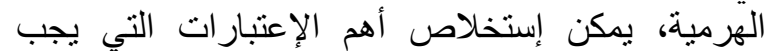
مراعاتها عند تغيير الثقافة التنظيمية للمراكز الإرشادية

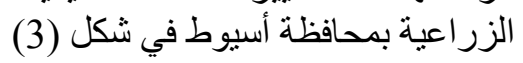

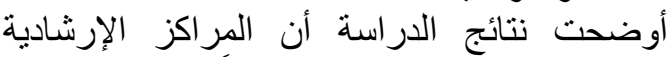

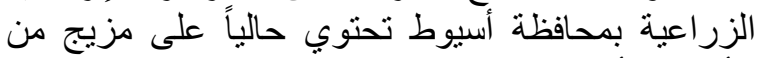
الأنواع الأربعة للثقافة التنظيمية تسودها التئية الثقافة الهرمية،

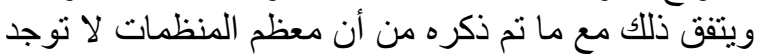

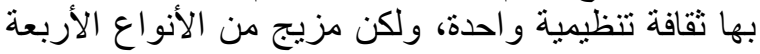

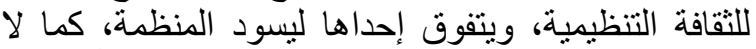

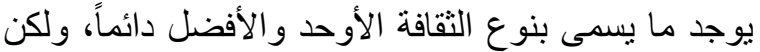

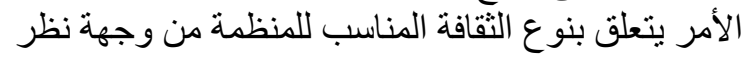




\section{REFERENCES}

Abbink J. (2015). Diagnosing and changing organizational culture to meet the necessary conditions for implementing the lead user method, M.Sc. Thesis, University of Twente, The Netherlands. Available at: http://essay.utwente.

nl/68017/1/Thesis_2020-08-

2015_20FINAL_Abbink_Gecensureerd.pdf

Adewale O. and Anthonia A. (2013). Impact of organizational culture on human resource practices: A study of selected Nigerian private Universities, J. Competitiveness, 5 (4): 115-133.

Beric M. (2007). Culture, dignity and empowerment, $\quad \mathrm{Six}^{\text {th }}$ Pan-European Conference on International Relations, Turin, Italy. Available at: http://www.eisanet.org/bebruga/eisa/files/events/turin/Mile na-

Culture,\%20Dignity\%20and\%20Empower ment.pdf

Berrio A. (2003). An organizational culture assessment using the competing values framework: A profile of Ohio state university extension, J. Exten.,41(2).

Cameron K. and Quinn R. (1999). Diagnosing and changing organizational culture: Based on the competing values framework, Prentice Hall Series in Organizational Development, Upper Saddle River, NJ.

Cameron K. and Quinn R. (2006). Diagnosing and changing organizational culture: Based on the competing values framework, Revised Edition, Jossey-Bass, San Francisco, USA.

Cameron K. and Quinn R. (2011). Diagnosing and changing organizational culture: Based on the competing values framework, $3^{\text {rd }}$ (Ed.), Jossey-Bass, San Francisco, USA.

Denison D. , Nieminen L. and Kotrba L. (2014). Diagnosing organizational cultures: A conceptual and empirical review of culture effectiveness surveys. Euro. J. Work and Organiz.Psychol., 23 (1): 145-161.

Fox J. (2013) Analyzing the organizational culture of Yolo County using two assessment models, M.Sc. Thesis, California State University, USA. Available at:http://www.csus.edu/ppa/thesis-

project/bank/2013/fox.pdf

$$
\begin{aligned}
& \text { 6.المراجع } \\
& \text { الإرشادية، متاح على: }
\end{aligned}
$$

http://caae-eg.com/index.php/2012-12-2510-49-01/2010-09-18-16-52-40.html

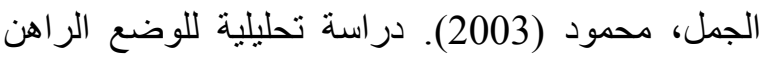

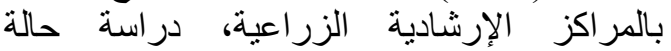
بمحافظة الدقهلية، المؤتمر الزية السادس للإِرشاد

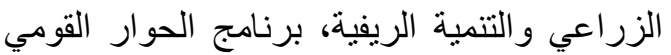

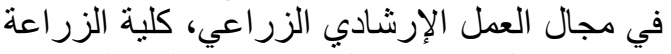

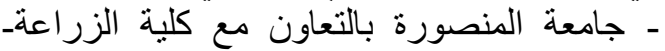
جامعة جويلف الكندية.

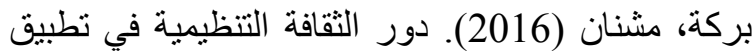

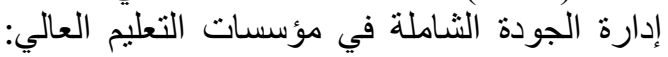

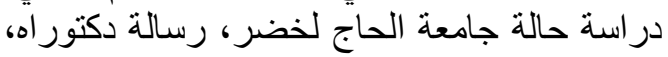

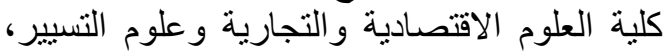
جامعة الحاج لخضر ، الجز ائر. متاح على:

http://theses.univ-

batna.dz/index.php?option=com_docm an\&task=doc_download\&gid=4989\&It emid $=2$

جو اد، شوقي (2010).المرجع المتكامل في إدارة الأعمال: منظور كلي. دار الحامد للنشر و التوزيع، عمان،

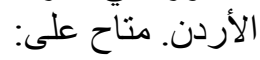

https://books.google.com.eg/

$$
\begin{aligned}
& \text { ز هران، بحيى (1998). مدخل الاليل التدريبى لأساسيات }
\end{aligned}
$$

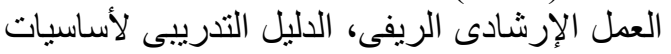

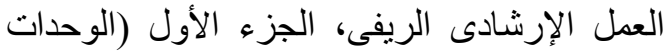

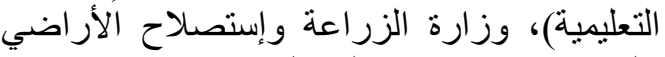

$$
\begin{aligned}
& \text { بالتعاون مع جامعة جويلف الكندية. } \\
& \text { سالم، إلياس (2006). تأثير الثقافة التنظيمية على أداء }
\end{aligned}
$$

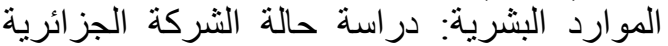

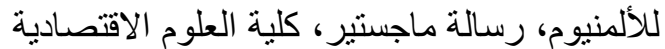

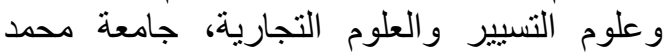

$$
\begin{aligned}
& \text { بوضياف بالمسيلة، الجزئر ائر. متاح على: } \\
& \text { الزر اعة- جامعة جويلف الكندية. }
\end{aligned}
$$


García L., Sanchez M., Cuevas H., Hernández R. and Vargas B. (2012). Organizational culture diagnostic in two Mexican technological Universities. Innovación Desarrollo Tecnológico Revista Digital, 4 (4): 1-20.

Hämmal G. and Vadi M. (2010). Diagnosing organizational culture through metaphors and task and relationship orientations. University of Tartu, Estonia. Available at: https://papers.ssrn.com/sol3/papers.cfm?abs tract_id $=1578902$

Igo T. and Skitmore M. (2006). Diagnosing the organizational culture of an Australian engineering consultancy using the competing values framework. Construc. Innov., 6(2):121-139.

Karsters A. (2011) Measuring the organizational culture at Telesur, Master Thesis, Maastricht School of Management, The Netherlands. Available at:

http://www.fhrinstitute.org/pluginfile.php/1 28/mod_data/content/763/Measuring_the _ Organizational Culture at Telesur by $\mathrm{Ar}$ nold_Karsters_MBA6.pdf

Karthikeyan C., Sendikumar R. and Jaganathan D. (2008). A Textbook of agricultural extension management, Atlantic Publishers and Distributers, New Delhi, India. https://books.google.com.eg/

Lunenburg F. (2011). Organizational cultureperformance relationships: Views of excellence and theory Z, Nat. Forum Edu. Admin. Supervi. J., 29 (4): 1-10.

OCAI Online (2012). OCAI Report, The Netherlands. Available at: https://www.ocaionline.com/userfiles/file/ocai_enterprise_ex ample_report.pdf
Rapidbi (2007). Organizational diagnosis and development, England. Available at: https://rapidbi.com/organizationaldiagnosis and development/

Schauber A. (2001) Effecting extension organizational change toward cultural diversity: A conceptual framework, Journal of Extension, 39 (3). Available at: https://www.joe.org/joe/2001june/a1.php

Schein E. (1990). Organizational culture, The Amer. Psychol. Ass., 45(2): 109-119.

Schein E. (2004). Organizational culture and leadership: A dynamic view, ( $3^{\text {rd }}$ ed.), Jossey-Bass San Fracisco, USA.

Suderman J. (2012). Using the organizational cultural assessment (OCAI) as a tool for new team development. J.of Practi. Consul., 4 (1): 52-58.

Tănase I. (2015). The importance of organizational culture based on culture transfer. Proceedings of the $9^{\text {th }}$ International Management Conference, Management and Innovation for Competitive Advantage. Bucharest, Romania. Available at: http://conferinta.management.ase.ro/archive s/2015/ pdf/89.pdf

Tharp B. (2009). Diagnosing organizational culture, Haworth, Organizational Culture White Paper, USA. Available at: http://la.haworth.com/docs/defaultsource/white-papers/diagnosing-orgculture_61-pdf-28531.pdf?sfvrsn=6

Wikipedia (2011). Diagnosis, The Free Encyclopedia. Available at: https://en.wikipedia.org/wiki/Diagnosis

Woszczyna K. (2014). The importance of rganizational culture for innovation in the company. Forum Scientiae Oeconomia, 2 (3):27-39. 